\title{
A review on friction-based joining of dissimilar aluminum-steel joints
}

\author{
Kush P. Mehta ${ }^{\text {a) }}$ \\ Department of Mechanical Engineering, School of Technology (SOT), Pandit Deendayal Petroleum University \\ (PDPU), Gandhinagar 382007, Gujarat, India
}

(Received 15 July 2018; accepted 21 August 2018)

\begin{abstract}
This article showcases details on enumerative information of dissimilar aluminum (Al) to steel welds manufactured using different friction-based welding processes with an emphasis on the description of the manufacturing process, influence of parameters, microstructural variations, formation of intermetallic compounds (IMCs), and variations in mechanical properties. Friction-based welding processes such as friction welding, friction stir welding, hybrid friction stir welding, friction stir spot welding, friction stir spot fusion welding, friction stir scribe welding, friction stir brazing, friction melt bonding, friction stir dovetailing, friction bit joining, friction stir extrusion, and friction stir assisted diffusion welding are analyzed for the formation of dissimilar Al-steel joints. It can be summarized that friction-based joining processes have great potential to obtain sound Al-steel joints. The amount of frictional heat applied decides the type and volume fraction of IMCs that subsequently affects mechanical joint properties. Process variations and novel process parameters can enhance joint properties.
\end{abstract}

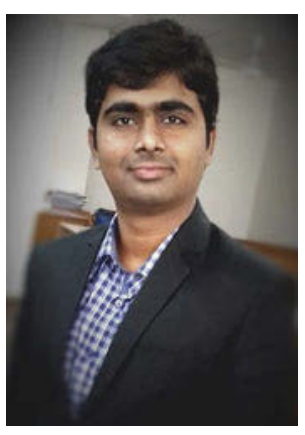

Kush P. Mehta

\begin{abstract}
Dr. Kush Mehta is an Assistant Professor in the Department of Mechanical Engineering, School of Technology (SoT), Pandit Deendayal Petroleum University (PDPU), Gandhinagar, Gujarat, India. He obtained his PhD in Mechanical Engineering with specialization in friction stir welding. His current research activities cover areas of advanced welding techniques, dissimilar welding, friction welding, friction stir welding, hot wire tungsten inert gas welding, advanced materials processing, and hybrid joining processes. He is actively involved in the activities of national professional bodies related to engineering and welding as a young researcher.
\end{abstract}

\section{INTRODUCTION}

Dissimilar joints of aluminum (Al)-steel have acquired substantial applications in different sectors of industries including majority in automotive, marine, aerospace, and chemical sectors, furthermore, day by day increasing along with development in technologies. ${ }^{1-4}$ The applications of $\mathrm{Al}-$ steel joints such as wind shield frame, bumper reinforcement, center pillar, and floor pan are existed in automotive structures and can be expanded in future. ${ }^{3-5}$ The use of dissimilar Al-steel joints in a product leads to the sustainable advantages such as reduction of overall cost by considering price differences of both the materials, minimizing weight of the component

\footnotetext{
a) Address all correspondence to this author. e-mail: kush_2312@yahoo.com DOI: $10.1557 /$ jmr.2018.332
}

taking into account density differences of both the materials, benefit on combination of light weight $\mathrm{Al}$ to high strength steel material, and hybrid properties availability at two different ends. ${ }^{6,7}$ However, the welding of dissimilar Al-steel materials is complicated due to complexity in compatibility of both the materials during mixing in each other. ${ }^{6,8}$ Specific differences in properties of $\mathrm{Al}$ and steel materials are mentioned subsequently. The difference in melting temperature between $\mathrm{Al}$ and steel is around $850{ }^{\circ} \mathrm{C}$. The ability to form oxides at distinct temperature is contrast for $\mathrm{Al}$ and steel materials. The coefficient of thermal expansion and specific heat of the $\mathrm{Al}$ material are almost twice than the steel material. ${ }^{1}$ The thermal conductivity of the Al material is six times higher than the that of the steel material. The Al material has three times higher modulus of elasticity than steel. ${ }^{6}$ $\mathrm{Al}$ and steel are having very poor solubility in each other. 
The electrochemical difference between $\mathrm{Al}$ and steel is 1.22 volts. ${ }^{1,6}$ These dissimilarities in thermophysical, chemical, and mechanical properties of Al-steel materials lead to disadvantages such as formation of intermetallic compounds (IMCs), heat-affected zone (HAZ), metallurgical precipitation, defects, distortion, and deterioration of mechanical joint properties. ${ }^{1,3,6,9,10}$

Considering these factors, joining processes such as brazing, ${ }^{11-13}$ gas tungsten arc welding (GTAW), ${ }^{14,15}$ gas metal arc welding, ${ }^{16,17}$ metal inert gas welding, ${ }^{18}$ laser welding, ${ }^{14,19-22}$ hybrid welding, ${ }^{23-26}$ resistance spot welding, ${ }^{27-29}$ explosive welding, ${ }^{30}$ magnetic pulse welding, ${ }^{31,32}$ cold metal transfer, ${ }^{33,34}$ ultrasonic welding, ${ }^{35}$ and friction-based welding processes ${ }^{1,3,6}$ are investigated in different literature studies. Out of all these processes, arc welding processes are viewed as nonrecommended processes to obtain successful dissimilar Al-steel welds based on their process aspects of melting and solidification caused by arc. Besides, friction-based welding can be considered as the most feasible solution to overcome the aforementioned problems associated with dissimilar $\mathrm{Al}-$ steel welds by bearing in mind their solid state nature and low heat input conditions. ${ }^{1,3,6}$ Different frictionbased welding processes such as friction welding, friction stir welding (FSW), hybrid friction stir welding (HFSW), friction stir spot welding (FSSW), friction stir spot fusion welding (FSSFW), friction stir scribe welding, friction stir brazing (FSB), friction stir dovetailing (FSD), friction bit joining (FBJ), friction melt bonding (FMB), friction stir extrusion (FSE), and friction stir assisted diffusion welding (FSADW) are analyzed for dissimilar Al-steel joints based on previous literature studies. However, the collective information and comparison of joint formation with different friction-based processes have never been attempted for publication hitherto to the extent of author's knowledge. There is a need to show collective informations on these literature studies in one single document by taking into account the importance of dissimilar Al-steel joints' and properties' variations in the weld area. As a consequence, comprehensive understanding is developed through this article, which showcases details on dissimilar Al-steel joint manufactured by the above-mentioned friction-based welding for its process description, influence of parameters, microstructural variations, formation of IMCs, and variations in mechanical properties.

\section{A. Binary phase diagram and IMCs}

$\mathrm{Al}$ and steel materials are having nearly zero mutual solubility that subsequently leads to form IMCs of $\mathrm{Fe}_{x} \mathrm{Al}_{x}{ }^{36}$ The formation of IMCs is dependent on solid state reactions between these two materials of $\mathrm{Fe}$ and $\mathrm{Al}^{37}$ Interactions of at.\% of $\mathrm{Fe}$ and $\mathrm{Al}$ materials decide the type of the IMC phase. The binary phase diagram of
$\mathrm{Fe}$ and $\mathrm{Al}$ is shown in Fig. 1 to understand the stand of different IMCs and reactions of $\mathrm{Fe}$ and $\mathrm{Al}$ with temperature interactions. Parameters such as time, temperature, pressure, and chemical compositions govern the formation of these IMCs, which is consequently depended on welding parameters and process conditions. ${ }^{36,37} \mathrm{Al}$ and Fe undergo interchanging as a function of small solute diffusion, movement of grain boundaries, and number of vacancies in the scale of atom, during a welding process. It can be seen from Fig. 1 that nonstoichiometric IMCs such as $\mathrm{FeAl}, \mathrm{FeAl}_{2}, \mathrm{Fe}_{3} \mathrm{Al}, \mathrm{Fe}_{2} \mathrm{Al}_{3}, \mathrm{Fe}_{2} \mathrm{Al}_{5}, \mathrm{FeAl}_{3}$, and $\mathrm{FeAl}_{6}$ are formed during the bonding between $\mathrm{Al}$ and steel-based alloys. ${ }^{1,36,37}$ The formation of IMCs are depended on the chemical potential of $\mathrm{Al}$ and $\mathrm{Fe}$, phase nucleation at the beginning of interdifusion, and mobility of alloying elements, which are subsequently affected by thermodynamic conditions of the process. ${ }^{38}$ Most of these IMCs are very hard and brittle than the $\mathrm{Al}$ and $\mathrm{Fe}$ base materials. The IMCs of $\mathrm{FeAl}_{2}, \mathrm{Fe}_{2} \mathrm{Al}_{5}$, and $\mathrm{FeAl}_{3}$ are most hard compounds among all the mentioned phases, as they consist of hardness more than 1000 VHN. ${ }^{1,36,37}$ Apart from differences in hardness, the crystal structures are distinct for different IMCs. The summary on IMCs of the Al-Fe system for their crystal structures and hardness is presented in Table I. In the case of weld area, the IMCs are generally found in the layer form at the interface between $\mathrm{Al}$ and steel materials and that is considered as the weakest part of the weld. Therefore, the presence of IMCs is recommended as minimum as possible in terms of thickness and volume fraction. The type, size, and amount of IMC formation are dependent on heat input that is governed by the welding process parameters. A higher amount of IMCs are formed due to higher heat input; therefore, it is recommended to operate a welding process with less heat input to make dissimilar Al-steel joints. ${ }^{1,36,37}$ There are additional process parameters and some process modifications relative to the conventional process performed to improve the formation of IMCs in different friction-based welding processes. Further description of IMCs can be found in subsequent sections based on different frictionbased processes along with important analysis on microstructural features and variations in mechanical properties.

\section{FRICTION WELDING}

Friction welding is a conventional solid state welding process that uses frictional heat and pressure to obtain welding between parent materials. The frictional heat is generated with the help of relative movement of workpiece materials by means of rotation or reciprocating motions. ${ }^{39,40}$ Dissimilar welding of $\mathrm{Al}-$ steel can be successfully welded by the friction welding process as solid state welding leads to overcome problems of 


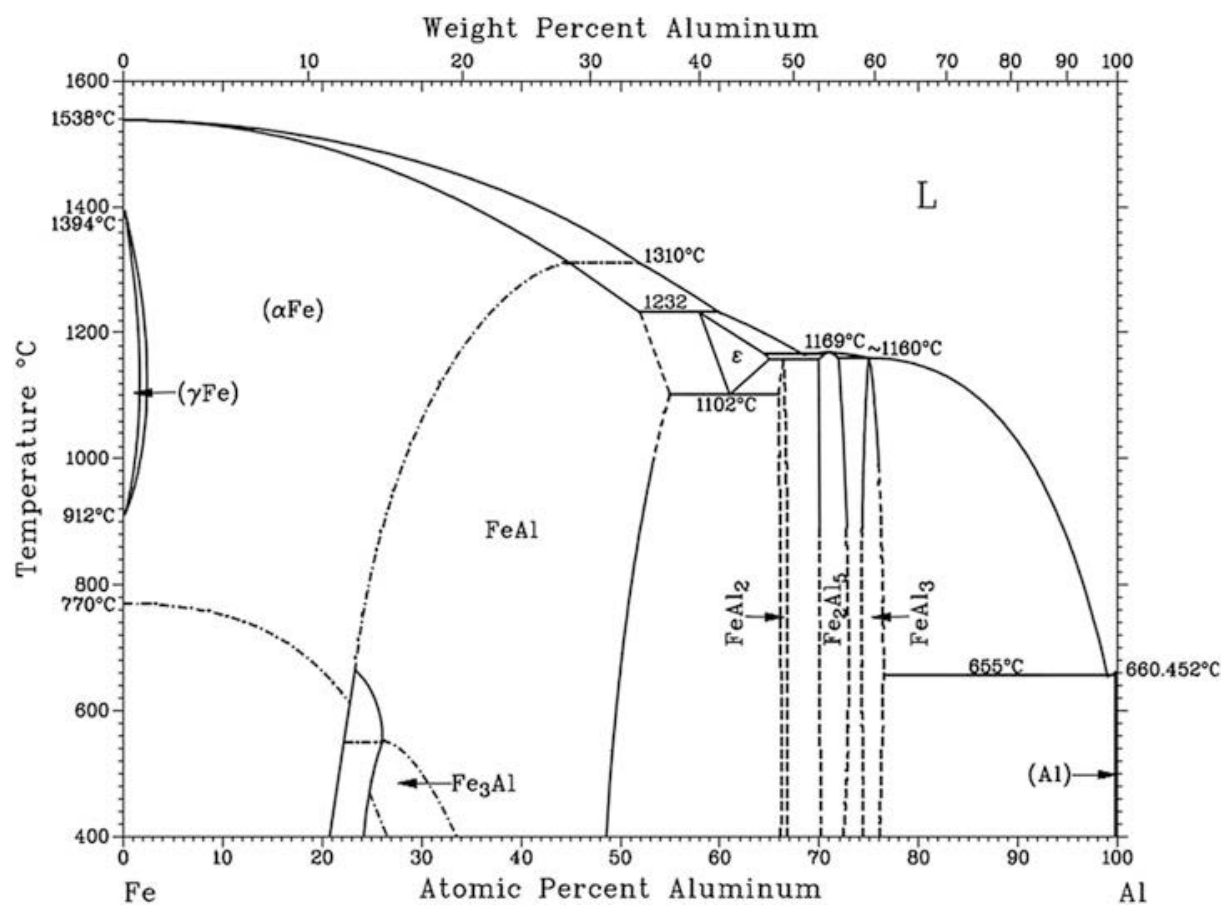

FIG. 1. Binary phase diagram of the Al-Fe system, with permission from Ref. 37.

TABLE I. Summary on crystal structure and hardness of different IMCs of the Al-Fe system. $1,36,37$

\begin{tabular}{lcc}
\hline \hline $\begin{array}{l}\text { Intermetallic } \\
\text { compound/phase }\end{array}$ & Crystal structure & Vickers hardness \\
\hline $\mathrm{Fe}-$ solid solution & BCC & $\ldots$ \\
$\mathrm{FeAl}$ & BCC & $470-667$ \\
$\mathrm{Fe}_{3} \mathrm{Al}$ & Ordered BCC & $330-368$ \\
$\mathrm{Fe}_{2} \mathrm{Al}_{3}$ & Complex cubic & $\ldots$ \\
$\mathrm{FeAl}_{2}$ & Triclinic & $1058-1070$ \\
$\mathrm{Fe}_{2} \mathrm{Al}_{5}$ & BCC orthorhombic & $1000-1158$ \\
$\mathrm{FeAl}_{3}$ & Highly complex monoclinic BCC & $\ldots$ \\
$\mathrm{Al}$-solid solution & FCC & $\ldots$ \\
\hline \hline
\end{tabular}

dissimilar welding. ${ }^{41-54}$ Cylindrical rods of Al-steel are generally welded by friction welding as it is most convenient for friction welding methodology. Process parameters such as rotational speed, axial pressure, time associated for heating, special edge preparations, use of interlayer, and holding of a specific material for rotation and stationary position are important as far as dissimilar Al-steel friction steel is concerned. ${ }^{41-54}$ Special edge preparations and holding of the workpiece material are unique parameters in addition to the conventional parameters for dissimilar Al-steel friction welding as reported in some of the literature studies. ${ }^{47,54}$ Heat generation in friction welding is mainly dependent on the aforementioned process parameters of rotational speed and time. ${ }^{50}$ Hence, the formation of IMCs is majorly governed by these parameters as it is directly influenced by heat generation. ${ }^{41-54}$ Subsequently, the mechanical properties especially tensile strength and hardness are affected with variations in IMCs. ${ }^{41,45,51}$ Higher rotational speed and frictional time lead to higher heat generation that consequently increases the formation of IMCs in the weld zone and deteriorated the mechanical properties. ${ }^{41,45,51,54}$ The reaction layer of IMCs is found at the interface between $\mathrm{Al}$ and steel materials. This reaction layer of IMCs is required as thin as possible by controlling process parameters, which is characterized as the better joint phenomenon. The critical reaction layer of IMCs is recommended as thin as 1-2 $\mu \mathrm{m}$ for strong bond strength. However, even thinner than this dimension enhances the mechanical properties of joint. ${ }^{41-54}$ The thick layer of IMCs deteriorates the tensile strength and increases hardness while reduces ductility of the joint. The heat distribution is nonuniform in all the directions of the weld interface that in turn form a nonuniform layer of IMCs. The analysis of the Al-steel interface is considered as critical due to the formation of brittle IMCs at this location. Apart from the layer of IMCs at the interface, the random distribution of IMCs is also presented in the weld zone. Different IMC phases of $\mathrm{FeAl}, \mathrm{Fe}_{2} \mathrm{Al}_{5}$, and $\mathrm{FeAl}_{3}$ are reported in most of the literature studies of $\mathrm{Al}$ steel friction welding. ${ }^{41-54}$ The mechanism of solid state diffusion and mechanical intermixing are mainly responsible for the formation of different IMCs. ${ }^{41,45,51,54}$ The mechanical pressure mainly influences the flash effect which usually occurs at the $\mathrm{Al}$ side. Larger mechanical pressure leads to larger deformation of the $\mathrm{Al}$ material 
that in turn causes larger flash effect. ${ }^{41-54}$ On the other end, adequate flash of $\mathrm{Al}$ is mandatory as bonding between $\mathrm{Al}$ and steel starts from the outer region of the faying surface and afterward goes toward the center of the faying surface. Due to this, the formation of the IMC layer is found thicker at the outer region and thinner at center as shown in Fig. 2.

Microstructural features are affected by friction welding parameters. In the case of $\mathrm{Al}$ and steel base materials of friction welding, $\mathrm{Al}$ is the softer material relative to steel that in turn leads to quick and large deformation. Moreover, the heat conductivity of $\mathrm{Al}$ is more than that of steel, and, therefore, large microstructural changes are noticed from the $\mathrm{Al}$ side due to high heat experiences. Since $\mathrm{Al}$ is a softer material than steel, large deformation of $\mathrm{Al}$ is obvious that consequently leads to large flash effect and microstructural changes at the $\mathrm{Al}$ side in the case of friction welding. ${ }^{41,45,51,54}$ There are four different microstructural changes reported at the $\mathrm{Al}$ side while another four microstructural changes are observed at the interface between $\mathrm{Al}$-steel joint by Wan and Huang et al. ${ }^{54}$ as shown in Fig. 3(a). The interface microstructure is important to understand considering the complexity of dissimilar Al-steel friction welded joints. The thickness of the reaction layer can be estimated under the diffusion process control by the equation of $X=\sqrt{ } t$ $\left[K_{\mathrm{o}} \cdot \exp (-Q / R T)\right],{ }^{6,43}$ where $X$ is the thickness of the reaction layer $(\mathrm{mm}), t$ is the diffusion time $(\mathrm{s}), K_{\mathrm{o}}$ is a constant, $Q$ is the activation energy (J) for the growth of the layer, $R$ is the gas constant, and $T$ is the absolute temperature $(\mathrm{K})$.

Region B of Fig. 3(a) indicates heat and deformation affected zone at the stainless steel side, which is

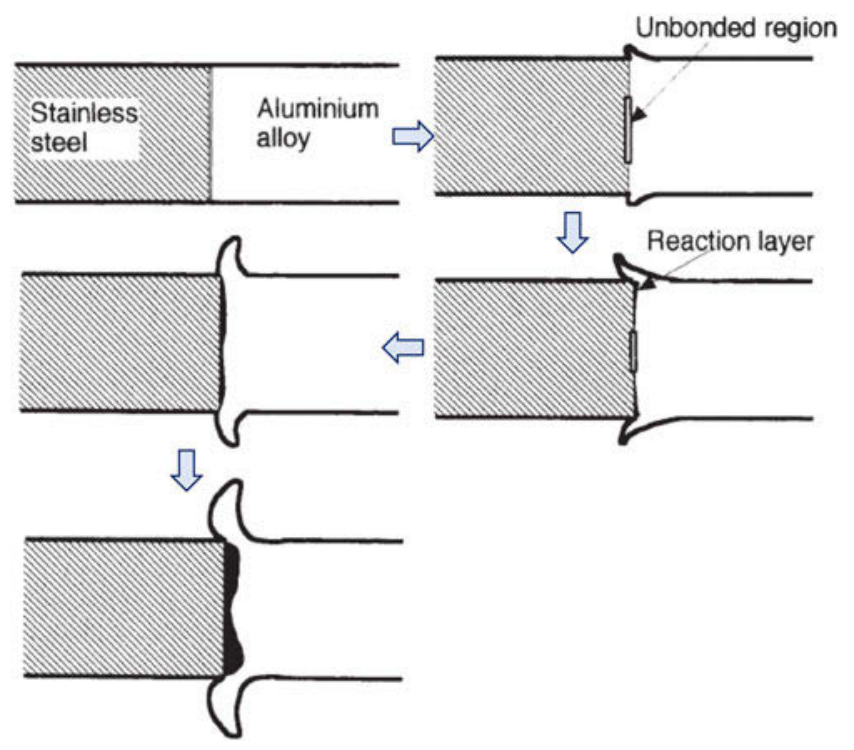

FIG. 2. Interlayer formation steps in dissimilar $\mathrm{Al}-$ steel friction welding, with permission from Ref. 42. generated due to frictional heat as well as plastic deformation. In this region, significantly smaller grains are reported with broadened crystal boundaries. ${ }^{41,45,51,54}$ Despite this, no major microstructural changes are occurred at the stainless steel side. The most critical microstructure zone is the interface of $\mathrm{Al}-$ steel that consists of the layer of IMCs as maximum interactions between $\mathrm{Al}$ and steel occur at this region. ${ }^{41-54} \mathrm{On}$ the other hand, major microstructural changes are observed at the $\mathrm{Al}$ side, which are noticed as complex to define. ${ }^{41,45,51,54}$ Figure 3 (b) shows the solid solution region that is created due to insufficient precipitation caused by experiencing highest temperature and fast cooling rate. Figure 3(c) shows the partial secondary recrystallized zone, wherein the combined effect of plastic deformation and high temperature is resulted in refined and equiaxed grains along with few large size grains. Next to it, the equiaxed recrystallized zone can be seen from Fig. 3(d) that is caused due to adequate temperature for grain growth recovery. Figure 3(e) shows the partial recrystallization zone that is generated due to low temperature than the region of the recrystallized zone. Figure 3(f) shows the plastically deformed zone that is formed due to mechanical deformation of the $\mathrm{Al}$ material caused by inadequate frictional heat and heat input as it is far from the interface of $\mathrm{Al}-$ steel. ${ }^{54}$ Some of these four zones are referred as the thermomechanically affected zone (TMAZ) in some of the literature studies. ${ }^{41,45,51,54}$ The less heat generation may result in less number of zones that subsequently treated as TMAZ based on material deformation and grain growth affected by heat input. For example, Wan et al. ${ }^{54}$ mentioned that the decrease in friction time reduces heat input, which in turn reduces the number of microstructural zones. Furthermore, the zones can be affected by only heat and that is treated as HAZ, if the mechanical deformation is not present.

The aforementioned microstructural features can be found for Al-steel friction welded joints without having any interlayer. The addition of the third material as the interlayer between Al-steel materials influences the microstructure of the interface along with the thickness of IMCs at the interface. In the case of Al-steel friction welding, without using any interlayer, brittle IMCs are formed while the interlayer material such as $\mathrm{Ag}$ generates IMC phases of $\mathrm{Ag}_{2} \mathrm{Al}$ and $\mathrm{FeAl}^{51}$ Other than $\mathrm{Ag}$, interlayer materials such as $\mathrm{Ni}$ and $\mathrm{Cu}$ can be used as an option to improve the bonding between dissimilar materials $\mathrm{Al}-$ steel. $^{51}$ However, the formation of IMCs such as $\mathrm{AlNi}, \mathrm{Al}_{3} \mathrm{Ni} \mathrm{AlNi}$, and $\mathrm{Al}_{3} \mathrm{Ni}$ for the $\mathrm{Ni}$ interlayer and formation of $\mathrm{CuAl}_{2}, \mathrm{CuAl}, \mathrm{Cu}_{9} \mathrm{Al}_{4} \mathrm{CuAl}_{2}$, and $\mathrm{CuAl}$ for the $\mathrm{Cu}$ interlayer are reported by Reddy et al. ${ }^{51}$ The use of interlayer is considered as the unique parameter of dissimilar friction welding in addition to conventional process parameters. 


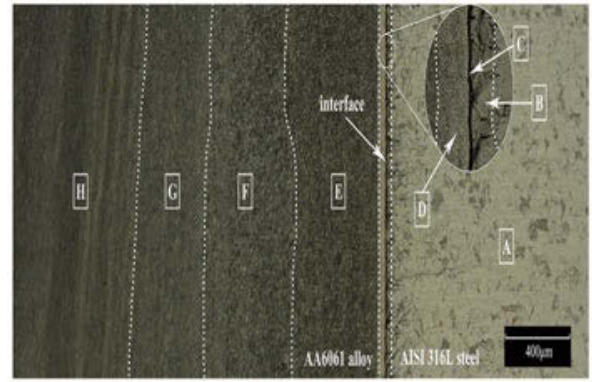

(a)

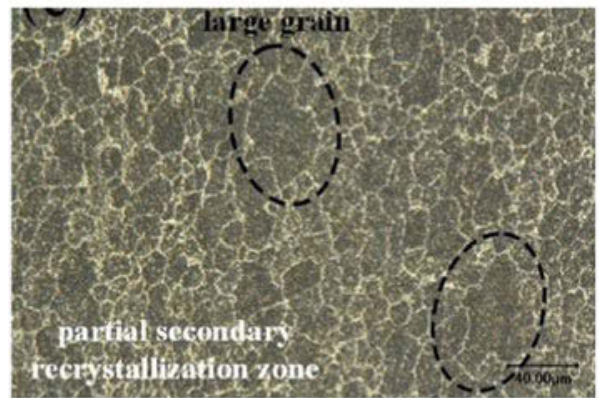

(c)

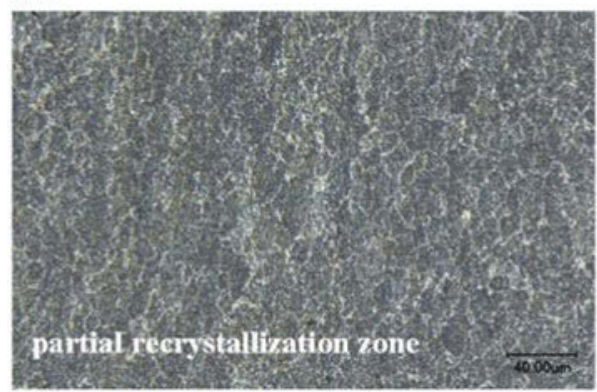

(e)

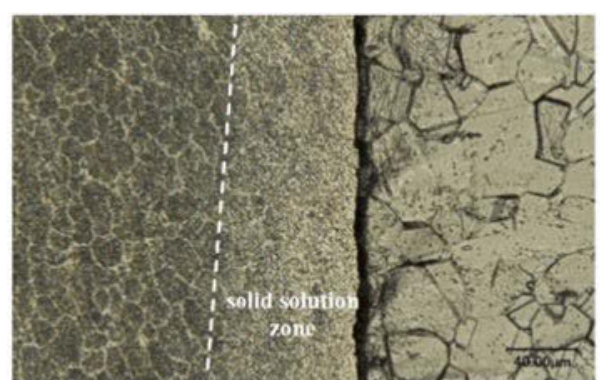

(b)

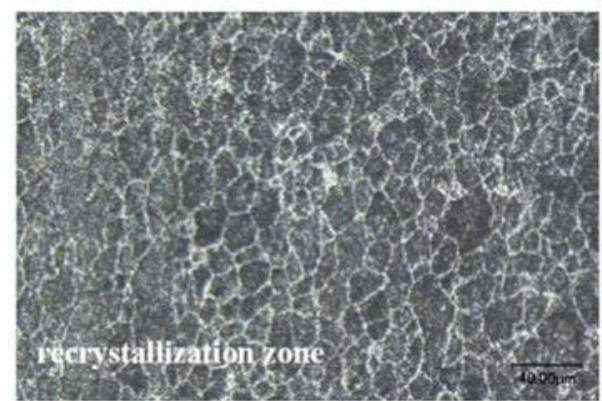

(d)

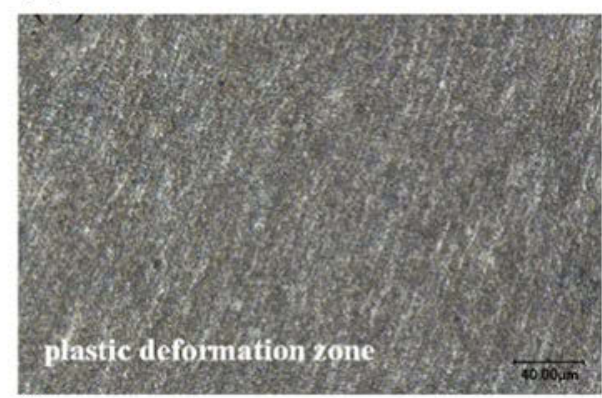

(f)

FIG. 3. Microstructural features of dissimilar Al-steel friction welds (a) Al-steel interface and different zones at Al sides, (b) solid solution zone at interface-region D of (a), (c) partial secondary recrystallized zone at Al-region E of (a), (d) recrystallized zone at Al-region F of (a), (e) partial recrystallized zone-region $\mathrm{G}$ of (a), (f) plastic deformation zone-region $\mathrm{H}$ of (a), with permission from Ref. 54.

The mechanical properties such as tensile strength, ductility, and hardness of dissimilar Al-steel friction welds are influenced by process parameters and working conditions. The tensile strength of dissimilar Al-steel joints is reported lower than the steel base material, considering the differences in the properties and complexity observed in microstructural features including IMCs. Acceptable tensile strength is considered as strength nearly equal to the Al-base material or more than that of Al. Controlled heat input through conventional process parameters of friction welding is recommended to obtain acceptable tensile strength. Sufficiently high axial pressure and lower deformation temperature through optimum friction time and relative speed can give better joint strength and ductility in the case of Al-steel friction welding. Literature studies suggested different ways such as the use of interlayer between Al-steel ${ }^{51}$ and contact surface modification, ${ }^{47,54}$ to improve tensile strength of dissimilar Al-steel joints apart from conventional friction welding. Application of the interlayer of $\mathrm{Ag}$ between $\mathrm{Al}$ and steel provides improved tensile strength than the conventional friction welding from 20 to $270 \mathrm{Mpa}^{51}$ It is also observed that the formation of IMC such as $\mathrm{Fe}_{2} \mathrm{Al}_{5}$ can be restricted by applying the $\mathrm{Ag}$ interlayer. On the other side, the $\mathrm{Ag}$ interlayer results in the formation of IMCs such as $\mathrm{Ag}_{2} \mathrm{Al}$ and $\mathrm{FeAl}$ that add ductility and subsequently improves hardness of the joint. ${ }^{51}$ Another approach to improve mechanical properties through novel parameter is edge preparations. ${ }^{47,54}$ The taper groove edge preparations of the steel material is recommended to improve joint strength relative to the conventional method of flat edge. The material flow and deformation pattern of joint area are significantly improved by this method of grove toward edge, which in turn resulted in enhancement of tensile strength. The improved intermixing by this 
method can result in improvement of the IMC layer. ${ }^{47}$ The tensile specimens are prone to brake from the joint interface as IMCs are present at this region. In this case, the fracture surfaces reveal brittle fracture that is but obvious due to the formation of IMCs. However, optimum heat input results in braking of tensile specimens from the deformed zone of the $\mathrm{Al}$ base material.

\section{FRICTION STIR WELDING}

FSW is a variant of friction welding, invented at The Welding Institute (TWI) in $1991 .^{55,56}$ In the FSW process, the nonconsumable tool is applied to the surfaces of the workpieces to be joined as shown in Fig. 3. This nonconsumable tool consists of featured pin and shoulder, which is inserted into the workpiece until shoulder contacts the top surface of the workpiece. The rubbing action between tool surfaces and workpiece generates heat that in turn softens the material under tool shoulder. Following it, transverse movement of tool is given, which is responsible for the movement of the softened material from front to the trail of the tool. ${ }^{57}$ Upon cooling to room temperature, the recrystallized weld zone is obtained along with bonding between two workpieces. Axial pressure and tool tilt angle are used as process parameters that help to forge the material downward in the direction of tool axis to obtain full penetration equal to or more than pin length. Therefore, it can be noted that rotational speed, travel speed, axial force, tool tilt angle, and tool design are most important process parameters of the FSW process. ${ }^{55,56}$ The major advantage of FSW over friction welding is joint configurations. Apart from butt joint configuration mentioned in Fig. 4, FSW can be applied for different configurations such as lap joint, overlap joint, T joint, and L joint. ${ }^{55}$ Atomized spindle/robotic arm can be adopted in FSW, to follow complex contours that in turn provide welding of complex profiles. ${ }^{58}$ Formation of exit-hole as a cavity of pin shape that is left at the end phase of the process is a major disadvantage of the process, which can be solved by advanced refilling techniques. ${ }^{55,56,59}$

FSW can be applied to different dissimilar combinations such as $\mathrm{Al}$-steel, ${ }^{6} \mathrm{Al}-\mathrm{Cu},{ }^{60-63} \mathrm{Al}$-titanium, ${ }^{64}$ Al-magnesium, ${ }^{65}$ magnesium-steel, ${ }^{66}$ titanium-steel, ${ }^{67}$

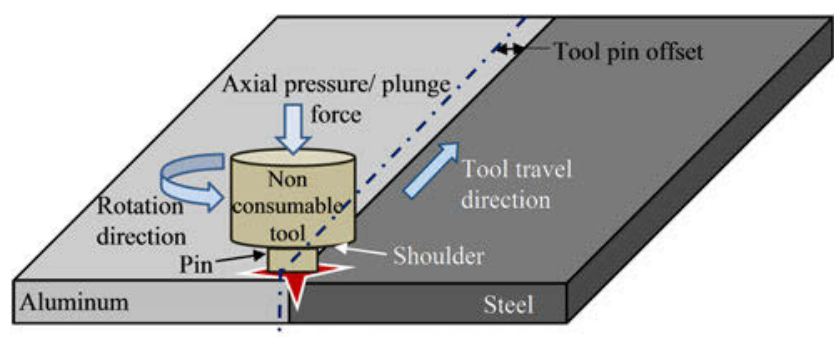

FIG. 4. Dissimilar FSW of steel to aluminum. and polymers-metals. ${ }^{68}$ The FSW process is one of the maximum investigated processes for the dissimilar joints considering the number of articles available. In the case of dissimilar Al-steel, the FSW process is having additional parameters such as tool pin offset at $\mathrm{Al}$ side and placing of the steel material at advancing side (i.e., the place where rotation direction and transverse direction are same), ${ }^{6}$ as shown in Fig. 4. Differences in properties can be adjusted with the help of these two new parameters. Pin offset in the Al material can be explained by the displacement of the tool to the Al base material, which is required because the deformation of both the materials cannot be attained at the same time of the operation. Pin offset in Al leads to major plastic deformation of the $\mathrm{Al}$ material while partial deformation of the steel material, which causes the dispersion of steel particles and that consequently lead to mixing of steel particles into the Al matrix. ${ }^{1,25,55,69-88}$ The size of these steel particles are dependent on tool pin offset majorly as well as heat input given by the process parameters of rotational speed, travel speed, and tool design. Another important parameter is the position of the workpiece, ${ }^{1,53,89,90}$ wherein, effective material flow and enhanced mixing can be obtained when steel is kept at the advancing side and $\mathrm{Al}$ at the retreating side. The tool pin disperses steel particles from the advancing side and drops into the $\mathrm{Al}$ matrix in an effective way, considering the same direction of rotation speed and travel speed. In the case of lap joint configuration, $\mathrm{Al}$ is kept on the top of steel and tool pin is inserted full in $\mathrm{Al}$ and minor in steel. The nonconsumable tool is having important elements such as pin diameter/dimensions, pin shape feature, shoulder diameter, shoulder surface geometry, shoulder to pin diameter ratio, and pin length that need to be fixed in such a way that effective dissimilar joint of Al-steel can be obtained. ${ }^{3,55,69-75,77-81,85,87-120}$ Shoulder diameter, its surface area, and shoulder to pin diameter ratio contribute maximum to the heat input that in turn influences joint formation. Pin dimensions and its features decide the material flow. The cylindrical pin is studied maximum for dissimilar Al-steel combinations as the dispersion of particles are more useful with the cylindrical pin in the case of dissimilar FSW. ${ }^{121}$ The ratio of rotational speed to travel speed is equally responsible for the heat input. The optimum ratio is recommended to perform the dissimilar FSW. The variation in thickness of the base material needs variable heat input according to dimensions that subsequently require change in tool design, rotational speed, and travel speed.

In terms of microstructure features, dissimilar FSW of $\mathrm{Al}-$ steel joints consists of distinct microstructural zones such as stir zone, TMAZ of Al, TMAZ of steel, HAZ of $\mathrm{Al}$, and HAZ of steel in addition to base material microstructures $3,6,53,67-73,75-79,83,85-118,122$ as shown in 
Fig. 5(a). The stir zone is an area, where bonding between steel and $\mathrm{Al}$ is taking place in FSW. Major plastic deformation of $\mathrm{Al}$ leads to recrystallized zone of its matrix wherein steel particles are mixed in a random manner. It is recommended to have uniform distribution of these steel particles in the $\mathrm{Al}$ matrix as shown in Fig. 5(b), to obtain enhanced mechanical properties and very less tool wear. However, the dispersion of steel particles should not be excessive. The size of steel particles dispersed from the steel material is recommended to as less as possible that helps in effective mixing with the Al matrix. The large-sized dispersed particles cause restriction in material flow and lead to the defects such as void, cavity, tunnel, and channel. As the stir zone consists of Al matrix and steel particles, it can be treated as the metal matrix composite zone. The stir zone interface with steel consists of the IMC layer while different phases of IMCs are also formed inside the stir zone. The presence of IMCs is reported in a layer form also around the steel particles [see Figs. 5(c) and 5(d)]. ${ }^{77}$ Traveling of $\mathrm{Fe}$ particles from the steel workpiece also influences the formation of IMCs. The IMC phases of $\mathrm{FeAl}_{2}, \mathrm{FeAl}_{3}$, $\mathrm{Al}_{13} \mathrm{Fe}_{4}$, and $\mathrm{Al}_{5} \mathrm{Fe}_{2}$ are detected in different literature studies of Al-steel FSW. ${ }^{69,106,113,123}$ The thickness of the
IMC layer at the interface is reported in the range of $<0.1 \mu \mathrm{m}-58.1 \mu \mathrm{m} ., 6,53,67-73,75-79,83,85-118,122$ Thickness of IMCs in the Al-steel FSW system is governed by shoulder diameter, shoulder to pin diameter ratio, rotational speed, and travel speed as heat input is largely influenced by these parameters. Rest of the parameters of FSW such as tool pin offset, material position, and axial pressure play significant role for the proportion of $\mathrm{Al}$ and steel interaction and hence IMCs are also influenced by them. Majority of literature studies related to Al-steel FSW have suggested that the IMC layer $<5 \mu \mathrm{m}$ can report better joint properties. $3,6,53,67-73,75-79,83,85-118,122$ Larger thickness of IMCs always deteriorates the mechanical properties of the joint that is evidenced in the case of Al-steel FSW in number of articles. ${ }^{69,106,113,123}$ The phases developed in the case of FSW are because of solid state diffusion with metal to metal interactions, interreaction with phases and lowest eutectic compositions, and inter reactions of phases and Fe. ${ }^{68,93,105,112,122}$ The stir zone consists of small size grain size of the Al-steel mixed material along with the presence of relatively large steel particles. On contrary to the increase in heat input via increase in rotational speed, the stirring effect is increased with an increase in rotational speed that further decreases

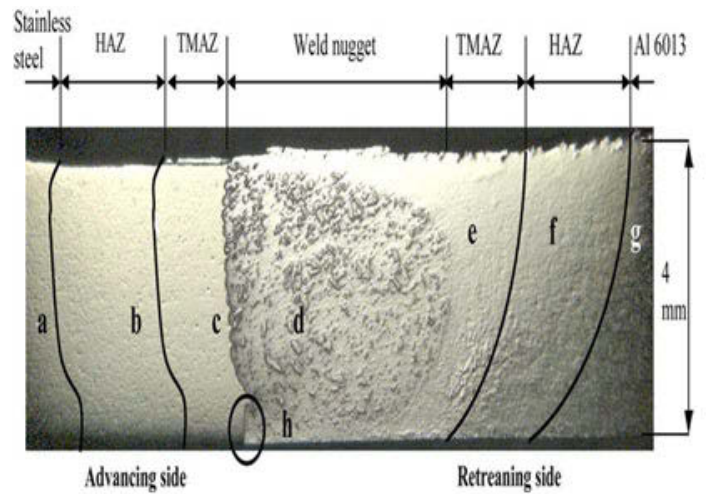

(a)

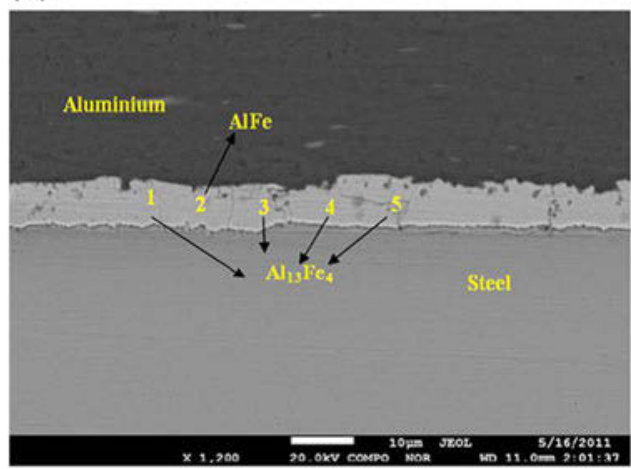

(c)

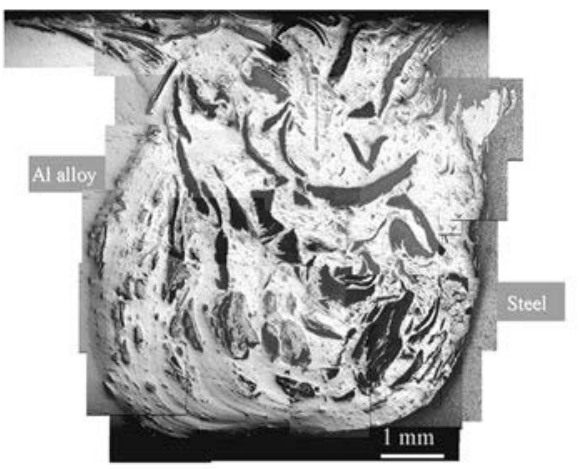

(b)

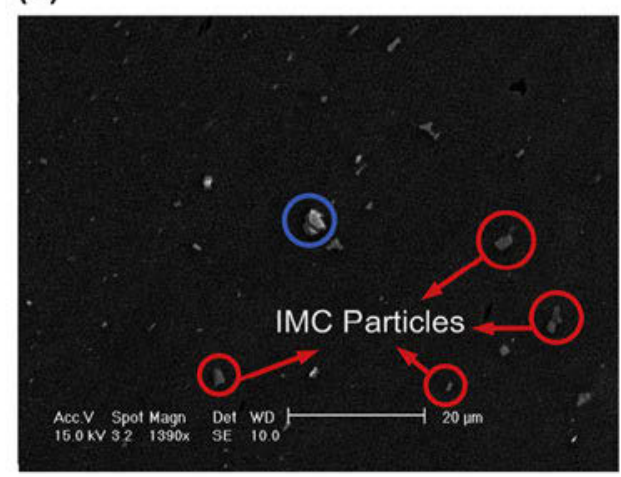

(d)

FIG. 5. Microstructural features of Al-steel FSW joints, (a) different zones indicated, with permission from Ref. 103, (b) complex stir zone, with permission from Ref. 102, (c) Al-steel interface with IMC layer, with permission from Ref. 107, and (d) presence of IMCs in the stir zone, with permission from Ref. 78. 
the grain size of the stir zone to ultrafine grains, whereas the grain size becomes coarsen when heat input increases through reduction in travel speed and increase in shoulder diameter. TMAZ is a zone that is developed due to the effects of thermal and mechanical deformation under the shoulder of the tool. The grains of TMAZ are deformed and elongated due to stirring effects. The $\mathrm{Al}$ side is largely affected by TMAZ compared to the steel side and tool is displaced toward the $\mathrm{Al}$ side in the case of Al-steel FSW. $\mathrm{HAZ}$ is a zone that is adjacent to the TMAZ and no major changes of grain size are observed relative to the respective base material. ${ }^{103}$ However, some of the literature studies have reported increased grain size in HAZ relative to the base material due to thermal effects. ${ }^{79}$

In the case of lap joint configuration, the stir zone consists of different microstructural behaviors than butt joint configurations as workpiece materials are lapped. In the case of lap joint, the $\mathrm{Al}$ is kept upward to the steel base material and hence the stir zone behaves like dynamically recrystallized zone with ultrafine grains majorly in $\mathrm{Al}$. The interface zone of $\mathrm{Al}$-steel is identified as metal matrix zone, where the dynamically recrystallized micro-structure is reported. Ultrafine grain size is generally reported at this stirred area due to large mechanical deformation and recrystallization. In addition to this, steel fragments are distributed in the Al matrix similar like butt joint configuration. However, in the case of lap joint configurations, the distribution of steel fragments is horizontal in direction that is different than the butt joint configuration. IMCs are presented in a direction of horizontal along the base material interaction surfaces. TMAZ and HAZ are formed like conventional FSW of similar materials. However, variations of zones are reported in the vertical direction as the dissimilar materials consist of variation properties.

Mechanical properties such as tensile properties and hardness are studied in majority of the literature studies. $3,6,53,67-73,75-79,83,85-118,122$ These properties are greatly influenced by the mixing of $\mathrm{Al}$ and $\mathrm{Fe}$ fragments that is governed by FSW process parameters. High heat input conditions such as too low travel speed, very high rotational speed, and large shoulder diameter cause more material deformation that in turn detaches large fragments of Fe particles, which is difficult to mix with the $\mathrm{Al}$ matrix and results into the defects (such as voids and cracks). ${ }^{3,70,92,99,111}$ Voids and cracks are generated due to improper material flow caused due to large fragments of $\mathrm{Fe}$ particles. These defects subsequently reduce the tensile strength of the stir zone. Aside from high heat input conditions, less tool pin offset and wrong placement of workpiece material lead to large dispersion of $\mathrm{Fe}$ fragments that in turn generate same conditions of voids and cracks and subsequently reduces the tensile strength. ${ }^{69,72-75,88}$ Furthermore, higher heat input forms large amount of IMCs in the stir zone and makes it hard, brittle, and low strength zone. These IMCs cause major variations in the hardness at the stir zone, Al base material, and steel particles along with distinct microstructures. Hardness peak values are reported in different literature studies such as $350 \mathrm{HV},{ }^{92} 500 \mathrm{HV},{ }^{74} 400 \mathrm{HV},{ }^{90}$ $739 \mathrm{HV},{ }^{98} 376 \mathrm{HV},{ }^{100} 320 \mathrm{HV},{ }^{102} 250 \mathrm{HV},{ }^{103} 335$ $\mathrm{HV},{ }^{111} 350 \mathrm{HV},{ }^{74}$ and $270 \mathrm{HV} .{ }^{73}$ These differences are because of variations in IMCs in volume fractions. The thick layer of IMCs at the interface between stir zone and steel material is observed in the case of high heat input conditions that are consequently responsible for the brittle fracture of tensile specimens. Besides, insufficient material deformation is caused by low heat input conditions such as very high travel speed, low rotational speed, and small shoulder diameter. The defects such as tunnel, voids, and lack of fill are generated due to nonuniform material flow caused by insufficient material deformation. Therefore, optimum combination of process parameters is required to obtain better mechanical properties. However, the tensile strength of the stir zone is always less than or equal to the $\mathrm{Al}$ base material due to the dissimilarities in properties of both the materials of $\mathrm{Al}$ and steel.

The FSW process is expanded with different approaches such as application of $\mathrm{Zn}$ interlayer between $\mathrm{Al}$ and steel base material, ${ }^{71}$ scroll tool shoulder without pin, ${ }^{91}$ wave shape tool pin base for lap joint configurations, ${ }^{117}$ kneed type butt joint configuration, ${ }^{124}$ and cutting edge type tool pin. ${ }^{80}$ It is recommended to use third material layer as the interlayer between dissimilar materials in the case of FSW. The joint properties of Al-steel dissimilar welds can be enhanced by putting the thin $\mathrm{Zn}$ interlayer between base materials. The $\mathrm{Zn}$ interlayer enhances the formation of IMCs that in turn improves the strength of the joint while reduces hardness and brittleness of the joint. ${ }^{71}$ Wave shaped tool pin base has improved steel flow in the Al material with two passes of processing. ${ }^{117}$ However, obtained tensile strength from wave shaped tool pin base is not up to the mark relative to the conventional method. Cutting edge type of the tool is adopted to obtain enhanced distribution of steel particles in $\mathrm{Al}$ that in turn resulted into higher strength than the Al base material. This method is not so popular due to complex tool design and sticking of the base material on that complex tool.

\section{HYBRID FRICTION STIR WELDING}

HFSW can be interpreted as a combination of conventional FSW with another process. Combination of two processes can enhance the capability of the conventional manufacturing process. Dissimilar Al-steel joints are benefitted by HFSW as the differences in deformation 
behavior of both the materials can be managed by secondary heat source. Secondary heat source can be applied to the particular base material that helps in enhancing bonding between base materials. HFSW techniques such as GTAW-assisted FSW, laser-assisted FSW, arc-assisted FSW, and electrically assisted FSW. Bang et al. $^{25}$ studied GTAW-assisted FSW for dissimilar AA6061-T6 to 304 stainless steel through preheating effect applied on the stainless steel base material (at $2 \mathrm{~mm}$ away from the center line). The preheating of stainless steel can ensure tool wear reduction and subsequently enhances the material flow through increased deformation behavior of stainless steel. Tensile strength and ductility of the joint can be enhanced with GTAWassisted FSW. This approach causes finer grains in HAZ and TMAZ of the Al side relative to the stir zone as can be seen from Fig. 6. Similar stir zone of the Al material with steel particles is observed in GTAW-assisted FSW. However, severe plastic deformation and higher temperature attribute to slightly finer recrystallized grains in the stir zone compare to the stir zone of conventional FSW.

Laser-assisted FSW is investigated by Fei et al. ${ }^{76,125}$ for Al-steel dissimilar joint, wherein laser is applied as preheating source on the steel base material small distance away from the joint line similar like GTAWassisted FSW. It is always suggested with different heating assisted FSW approaches that the tool wear can be significantly reduced and travel speed can be increased. The stir zone of laser-assisted FSW is again like Fe particles mixed with the Al matrix without major changes in other zones. However, it is suggested that additional parameters enhance the microstructures and mechanical properties of the joints. It is suggested to keep predrill at the $\mathrm{Al}$ side while performing laser-assisted FSW to improve plunge phase and subsequent material flow. Due to the predrill factor, the layer of IMCs at that particular location is enhanced and consequently tensile strength is improved. ${ }^{76}$ Another additional factor of laserassisted FSW for Al-steel joint is filler material addition. Foil of the Ni material is recommended for Al-steel laserassisted FSW joint that augments the tensile strength of the joint as well as the ductility of the joint. On the other hand, $\mathrm{Zn}$ foil reduces the strength and increases the brittleness of the joint. The use of the $\mathrm{Ni}$ interlayer between $\mathrm{Al}$ and steel material is also mentioned in the section of friction welding as it improves mechanical
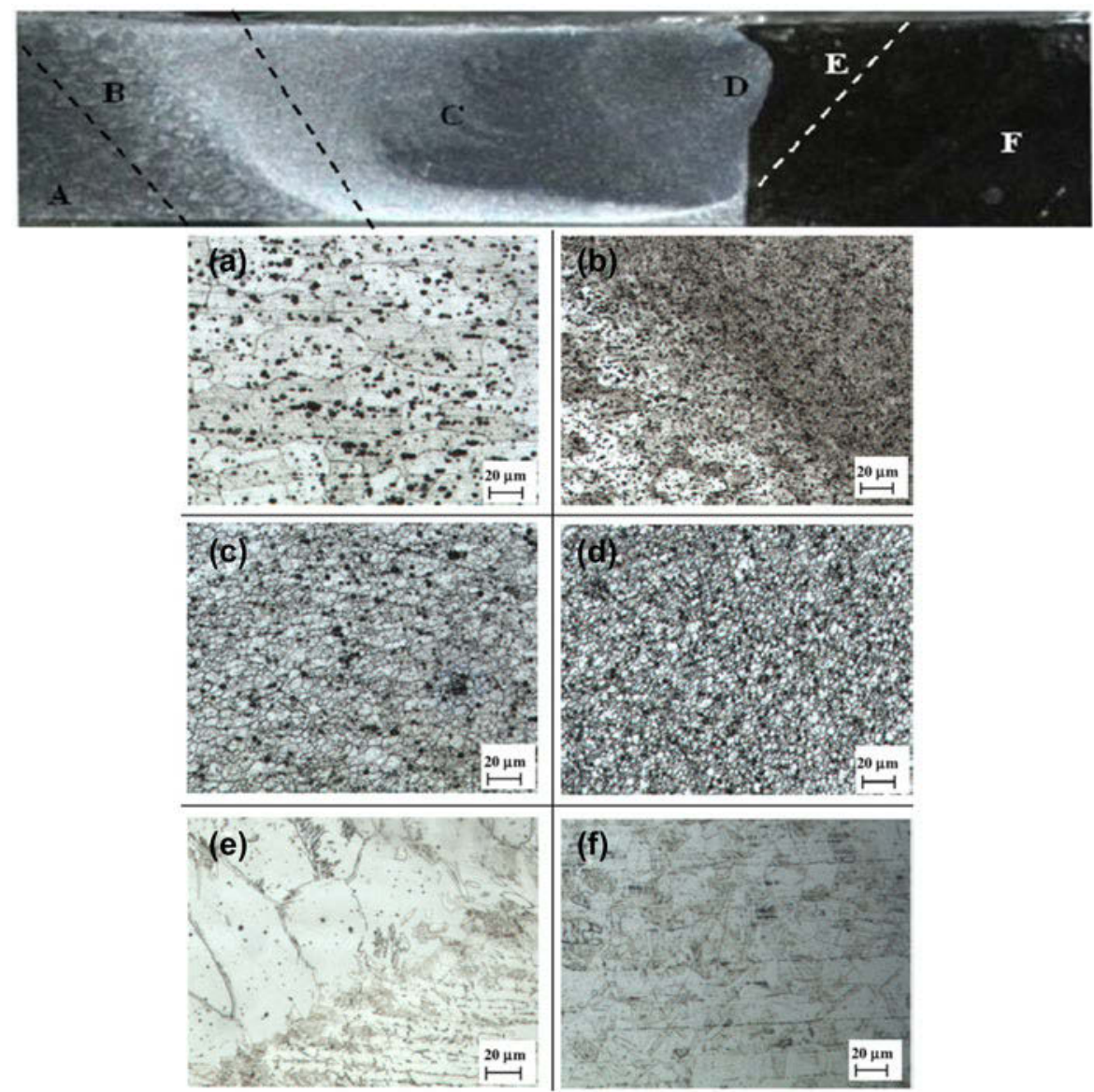

FIG. 6. Microstructural changes of dissimilar Al-steel GTAW assisted FSW joint: (a) Al base material, (b) TMAZ of Al side, (c) stir zone, (d, e) stir zone-steel interface-TMAZ of steel side, and (f) steel base material, with permission from Ref. 25. 
properties by having better metallurgy. Besides, the $\mathrm{Zn}$ interlayer is recommended in the case of previous section of conventional FSW, where brittleness and increase in hardness are the issues observed in line with hybrid FSW due to the formation of brittle IMCs. Electrically assisted FSW is a technique in which electrical resistance is applied as a preheating source that leads to effective electroplastic effect and enhances the formation of IMCs with improved micro interlock features at the stir zone that in turn improves the quality of joint. ${ }^{86}$ In the case of heating assisted FSW, process parameters such as distance between heating source to the FSW tool, angle and distance of heating source from the joint line, amount of heat supplied via heating source, and type of heating source used are the extra factors in addition to process parameters of FSW that are required to be considered. Preheating of steel leads to partial annealing effect and helps to soften the steel material at that particular location, which subsequently improves material flow and results in better joint properties.

\section{FRICTION STIR SPOT WELDING}

FSSW is developed from the process principle of FSW, which uses to make spot welds. ${ }^{126}$ The travel phase of the FSW process is completely eliminated in this process while the dwell phase is considered as an important phase of the FSSW process. Automobile structures of dissimilar Al-steel joints are applied with FSSW due to benefits over other spot welding processes. FSSW is an alternative method of resistance spot welding and mechanical fastening. FSSW is applied majorly in the case of lap joint configuration. Process parameters such as tool design, rotational speed, dwell time, depth of plunging, rate of plunging, and position of the workpiece material are considered as important as far as dissimilar Al-steel FSSW is concerned. ${ }^{82,91,123,127-143}$ Application of fixture is also considered as an important parameter when the joint configuration is complex. Double sided FSSW is developed for dissimilar Al-steel joints with special purpose fixture by Lyu et al. ${ }^{131}$ The heat input is majorly governed by tool diameter, rotational speed, and dwell time that subsequently affect the formation of IMCs. Besides, the material flow and mixing is highly dependent on penetrating depth and position of the workpiece material in lap configuration. ${ }^{138}$ The microstructural changes of FSSW are similar to the FSW process such as stir zone, TMAZ, and HAZ, as frictional heat softens the base material and subsequent recrystallization leads to joint formation. ${ }^{125-141}$ In the case of dissimilar Al-steel FSSW, the $\mathrm{Al}$ base material is suggested to keep on top of the steel base material as it is a soft material that subsequently leads to better plunge phase and recrystallized grain formation in the stir zone with particles of steel dispersion. By keeping $\mathrm{Al}$ on top of steel, the forces required for the plunge stage and tool wear are less. Moreover, the depth of the penetration of tool pin controls the dispersion of steel fragments. Smaller depth leads to fine dispersion and better mixing while higher depth results in large dispersion and generates defects. Besides, the zero penetration depth, i.e., tool pin penetration in the $\mathrm{Al}$ base material up to full thickness without penetrating into the steel base material is not recommended due to poor strength and joining mechanism. Solid state diffusion causes metallurgical bonding and forms IMCs at the interface between $\mathrm{Al}$ and steel in the case of FSSW without pin penetration in steel, whereas in addition to IMC formation, mechanical hooking and swirl layered microscopic mechanical lock effects improve the strengthening of Al-steel dissimilar joint. ${ }^{133}$ However, mechanical interlocking by the hocking effect is not advantageous when the hooking effect is large. Therefore, selection of pin length is critical. Generally, pin length is kept slightly higher than the thickness of the Al base material. Due to variations in properties of both the base materials, TMAZ, HAZ, and stir zone consist of different types of grains on both the sides of them. The deformation is high at the $\mathrm{Al}$ side and hence large TMAZ and HAZ are formed at the $\mathrm{Al}$ side. ${ }^{106,129,132,133,138}$ At the end of FSSW, the exit-hole formation is again occurred at the stir zone, which is resolved with the development of refilling techniques or pin less FSSW techniques. ${ }^{59,63,82,130,140}$ Scrolled shoulder tool of without pin is found as one of the methods to eliminate the exit-hole effect with improved material flow. ${ }^{91}$ However, cavity formation is always there with these types of techniques. Refill FSSW is a popular technique to obtain the exit-hole free stir zone in the case of dissimilar Al-steel joints (refer Fig. 7). Refill FSSW results in improved joint strength with improved material flow in the stir zone area. ${ }^{127}$ Vertical movement of the pin with additional pressure by sleeves fills the cavity formed during the FSSW process as shown in Fig. 7 that subsequently improves the microstructures of the stir zone and surroundings when compared with conventional FSSW. It is observed that dispersion of steel particles is significantly improved with refill FSSW. The formation of IMCs is observed in a layer form as mentioned in previous sections of different welding processes. A continuous layer of IMCs with its minimum thickness at the interface of $\mathrm{Al}-$ steel joints is recommended. ${ }^{59,63,82,130,140}$ The presence of brittle IMCs at the interface of $\mathrm{Al}-$ steel results in brittle fracture during shear testing. These brittle IMCs are responsible for having very high hardness at the joint interface as similar as mentioned in the case of FSW. Joint strength is considered better if it goes close to the $\mathrm{Al}$ base material with fracture from the Al base material. The exit-hole refilling by circular moving friction stir processing at the periphery of the exit-hole can also fill the cavity. ${ }^{82}$ 


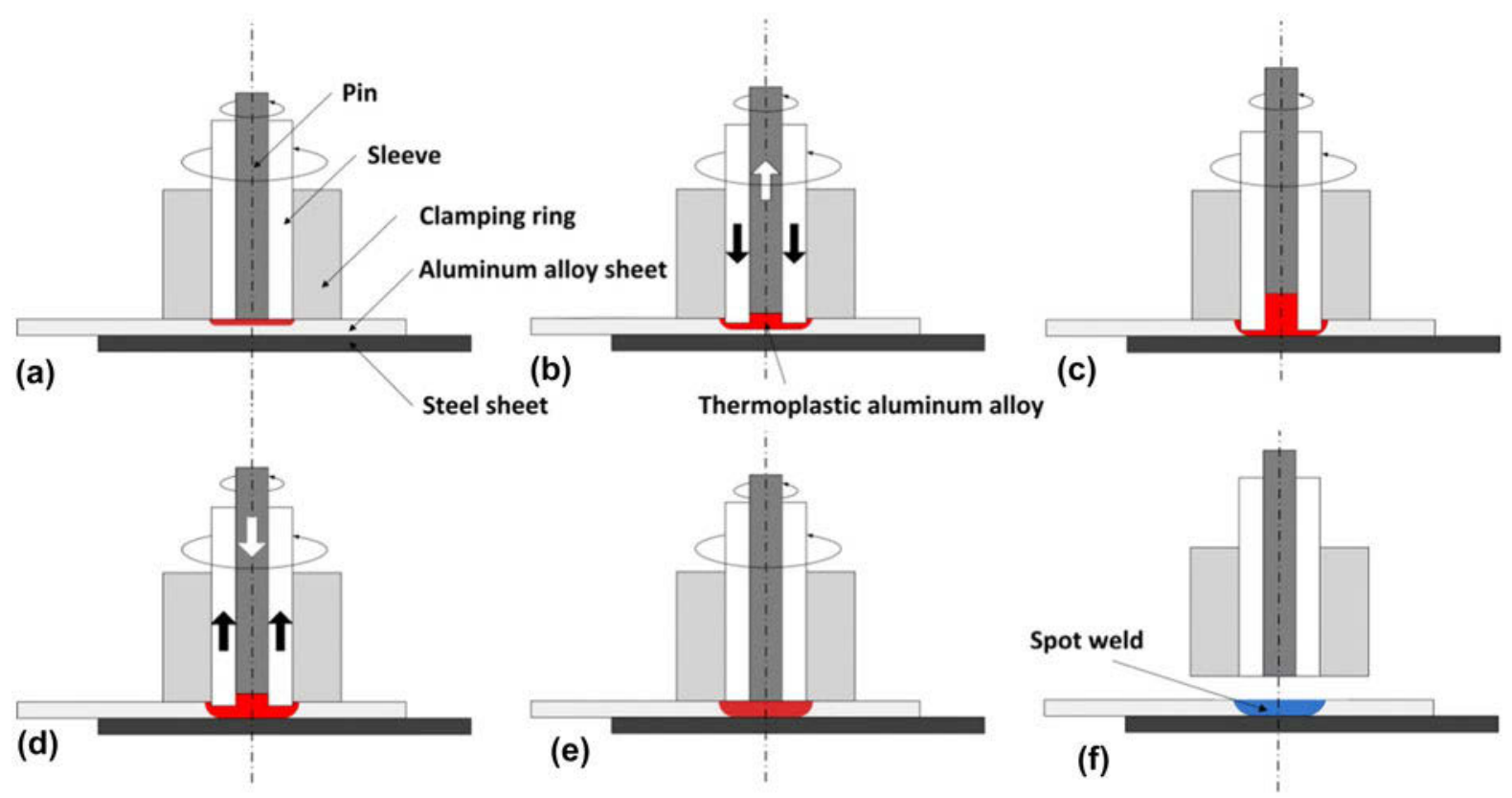

FIG. 7. Refill FSSW (a) before plunge, (b) plunge phase, (c) dwell phase, (d) refilling phase, (e) trim phase, and (f) retreating phase, with permission from Ref. 127.

However, this is not an effective one relative to refill FSSW, as another exit-hole by secondary process causes same difficulties.

\section{FRICTION STIR SCRIBE WELDING}

Friction stir scribe welding is a technique developed based on FSW that uses modified tool design to joint workpieces of lap joint configuration. The end surface of the tool pin consists of scribe that is hard material insert with very small length ${ }^{84,144}$ as shown in Fig. 8(a). This friction stir scribe welding technique is known as the hybrid combination of mechanical fastening and solid state joining. Dissimilar joint can be successfully obtained with friction stir scribe welding by inserting the tool pin into the low melting softer material (i.e., kept at top) along with scribe insertion in another material. $^{84,144}$ This causes huge plastic deformation at the pin area of the softer material and helps in dispersion of small particles from the bottom material and improves material mixing [see Fig. 8(b)]. This in turn forms hooklike interface with enhanced mechanical interlocking. The height of this hook is very important to govern mechanical properties such as joint strength. ${ }^{84,144}$ Important process parameters of friction stir scribe welding are tool design including scribe design, rotational speed, travel speed, tool tilt angle, and plunge depth that influence dissimilar joint properties. The scribe length is kept very small that helps in removing small particles of the hard material, which improves material mixing as also mentioned in previous sections. It can be suggested

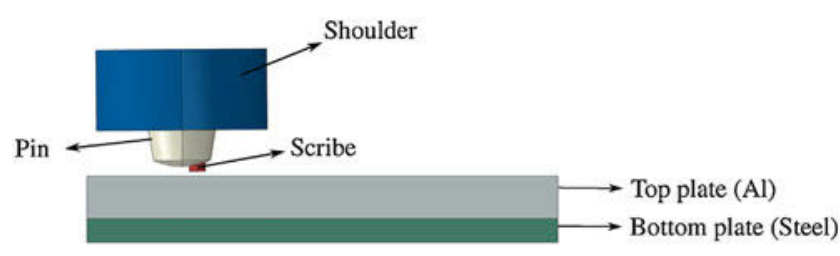

(a)

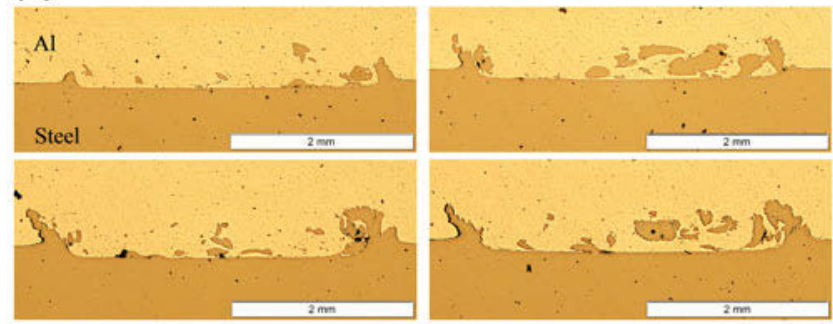

(b)

FIG. 8. (a) Friction stir scribe welding and (b) material mixing from friction stir scribe welding along the length, with permission from Ref. 144.

to keep $0.5 \mathrm{~mm}$ or less than that as scribe length while tool pin length is to be kept near to the $\mathrm{Al}$ base material or slightly higher than that considering plunge depth. ${ }^{84,144}$ However, the thickness of the workpiece is an important factor to decide scribe length and other tool dimensions. Formation of IMCs cannot be avoided with friction stir scribe welding of Al-steel joints. Similar IMC phases mentioned in the case of FSW are expected to form in this technique. ${ }^{84,144}$ However, dispersion of steel particles is different in this case that may affect volume fraction of IMC formation. Figure 8(b) shows that the 
dispersion of steel fragments is varied along the length of the weld. Therefore, IMCs are proposed as different in volume fraction along the length as well. In the case of galvanized steel to $\mathrm{Al}$ alloy friction stir scribe welding, formation of $\mathrm{Al}-\mathrm{Zn}$ solid solution is noted in addition to expected IMCs of the Al-steel binary system. ${ }^{143}$

\section{FRICTION STIR BRAZING}

FSB is again developed from the FSW process with an application of the third material as an interlayer between base materials of lap joint configuration. ${ }^{145,146}$ FSB is a process in which the pinless tool consists of shoulder applied on the $\mathrm{Al}$ workpiece surface that is kept on the top of the fixture. Besides, steel is kept at the most bottom side of the fixture while the interlayer material is applied in between $\mathrm{Al}$ and steel. The $\mathrm{Zn}$ material is applied as an interlayer material by Zhang et al. ${ }^{146}$ Refer Fig. 9 for FSB of the dissimilar Al-steel system. Multipasses are carried out to generate more amount of heat in the case of FSB. Process parameters such as rotational speed, travel speed, tool shoulder diameter, thickness of the interlayer material, and workpieces are considered important for Al-steel. ${ }^{146}$

As the tool pin is not present in the case of FSB, ${ }^{145,146}$ the microstructural variations are different compared to FSW and other FSW-based processes. Plastic deformation in stir zone and other features like dispersion of steel fragments/particles and hook type mechanical interlocking are avoided in the case of FSB. To have the reaction of $\mathrm{Al}-\mathrm{Zn}$ and $\mathrm{Zn}$-steel interfaces, frictional heat generated via rubbing action between shoulder and workpiece is transferred to the interface between $\mathrm{Al}-\mathrm{Zn}$-steel, which in turn melts the interlayer material of $\mathrm{Zn}$ and leads to the reactions. These reactions are caused due to interdiffusion and form a variety of IMCs and eutectics based on the $\mathrm{Zn}-\mathrm{Al}-\mathrm{Fe}$ ternary alloy. Different phases of $\mathrm{FeAl}_{3}(\mathrm{Zn})$ at $\mathrm{Al}$ side, $\mathrm{Fe}_{2} \mathrm{Al}_{5}(\mathrm{Zn})$ at steel side, and eutectics of the $\mathrm{Zn}-\mathrm{Al}$ super saturated structure are observed in FSB along with the presence of $\mathrm{FeAl}(\mathrm{Zn})$, and $\mathrm{Fe}_{2} \mathrm{Al}_{9}(\mathrm{Zn})$ due to interdiffusion and $\mathrm{Al}$ dissolution in the molten $\mathrm{Zn}$ phenomenon. ${ }^{146}$ Mentioned IMCs are reported in a layer form and the thickness of it varies from 25 to $3 \mu \mathrm{m} .{ }^{146}$ Continuous thickness of these IMCs is recommended for good quality joint with its minimum possible value.

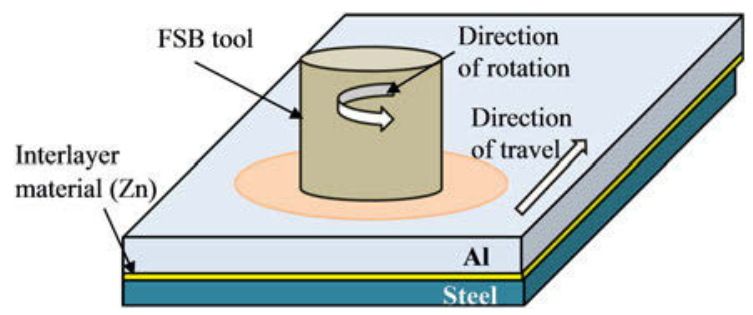

FIG. 9. Friction stir brazing of Al-steel.
Better shear tensile strength can be obtained when the thickness of IMCs is reported less, which is governed by process parameters. In the case of FSB, the workpiece thickness may be the constraint as the heat produced on the top surface must be transferred to the interface of $\mathrm{Al}-\mathrm{Zn}$-steel.

\section{FRICTION MELT BONDING}

FMB is a process to join Al-steel dissimilar materials in lap configuration with pin less shoulder as like FSB but without using the interlayer material. ${ }^{147}$ In addition to this, the steel material is positioned above the $\mathrm{Al}$ base material as shown in Fig. 10(a), unlike FSB and FSSW. Frictional heat is generated from the tool and transferred to the interface of $\mathrm{Al}-$ steel, which leads solid state plastic deformation that subsequently increases the temperature. Transfer of this heat to the $\mathrm{Al}$ base material leads to partial melting of it as that has lower melting point. This partial melting of $\mathrm{Al}$ forms localized pool at the contact interface as shown in Fig. 10(a), while the bottom part of $\mathrm{Al}$ remains in the solid state. Reaction of this localized melted $\mathrm{Al}$ and plasticized steel leads to joint formation. ${ }^{147}$ Process parameters such as rotational speed, travel speed, shoulder diameters, tool tilt angle, and workpiece thicknesses are important to consider. In the case of thicknesses, FMB is recommended for low thickness workpieces. Besides, workpiece materials of larger thicknesses cannot be joined due to problems in heat availability at the interface between Al-steel. Rest et al. ${ }^{147}$ performed successful experiments on $0.8 \mathrm{~mm}$ steel and $2 \mathrm{~mm} \mathrm{Al}$ alloy to obtain dissimilar joint by FMB. Microstructural variations of FMB are TMAZ, reactive layer consists of IMCs, and dendritic structure at solidified Al. Formation of IMCs in different layer forms are reported at the interface that can be confirmed by Fig. 10(b), and IMC phases such as $\mathrm{FeAl}_{3}$ at $\mathrm{Al}$ side and

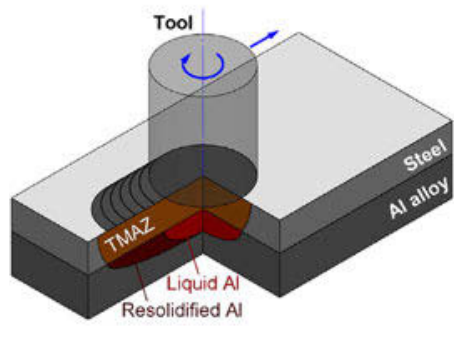

(a)

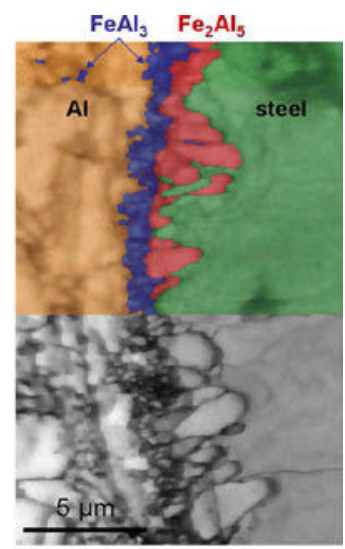

(b)
FIG. 10. Friction melt bonding (a) process principle and (b) formation of IMC-EBSD image, with permission from Ref. 147. 
$\mathrm{Fe}_{2} \mathrm{Al}_{5}$ at steel side are formed during the FMB process. ${ }^{147}$ Better tensile strength can be obtained with FMB for Al-steel joints after performing postweld heat treatment processes.

\section{FRICTION STIR SPOT FUSION WELDING}

FSSFW is a derived technique of FSSW for lap joint configuration, wherein hollow shouldered tool having an assembly embedded rod in it. FSSFW is a process in which the steel material is kept on the $\mathrm{Al}$ base material and special tool is inserted into it. ${ }^{148}$ The embedded rod in the hollow shouldered tool is used to avoid adhesion between shoulder surfaces and workpiece top surface after welding by moving it toward the end surface of the cylinder. Process parameters such as tool shoulder diameter, shoulder hollow diameter, rotational speed, dwell time, downward force, displacement after shoulder surface contacts the workpiece, and workpiece thicknesses are to be considered in the case of FSSFW. ${ }^{148}$ As mentioned in Sec. VIII, partial melting of $\mathrm{Al}$ can be achieved when frictional heat is transferred from the top surface of steel to Al that is kept below the steel. Similarly, the partial melting of $\mathrm{Al}$ is obtained, which is responsible for the bonding with the interdiffusion phenomenon. Formation of the IMC layer with phases of $\mathrm{Fe}_{2} \mathrm{Al}_{5}$ and $\mathrm{Fe}_{4} \mathrm{Al}_{13}$ is noted when low carbon steel is welded to the $\mathrm{Al}$ alloy of 6061-T6. ${ }^{148}$ Microstructural variations of FSSFW of Al-steel joint suggest that the layer of IMCs is thicker in the case of fusion zone relative to the deformation zone due to the strong interdiffusion phenomenon at the fusion zone. Appropriate range of IMCs thickness such as 6$17 \mu \mathrm{m}$ is suggested to enhance failure load during shear tensile testing. ${ }^{148}$ The material mixing and microstructural changes are suggested to be largely influenced by the thickness of the Al base material.

\section{FRICTION STIR ASSISTED DIFFUSION WELDING}

FSADW is a process promoted by the FSW process that is applied to lap joint configuration of Al-steel dissimilar joint, wherein $\mathrm{Al}$ is kept on top of steel. ${ }^{149}$ The tool used in FSW is used in the case of FSADW that consists of tool pin and shoulder with a difference of pin length. The pin length is kept slightly less (such as $0.2 \mathrm{~mm}$ ) than the thickness of the $\mathrm{Al}$ base material to avoid contact with the steel base material. ${ }^{149}$ Therefore, the stirring action is intended to transfer heat at the interface of Al-steel, which consequently causes diffusion at the interface. Microstructures of FSADW suggest the recrystallized stir zone and TMAZ in the Al material while the diffusive interlayer of IMCs can be reported at the interface of Al-steel. ${ }^{149}$ IMC phases such as $\mathrm{Al}_{5} \mathrm{Fe}_{2}$ and $\mathrm{AlFe}$ are reported due to solid state diffusive action

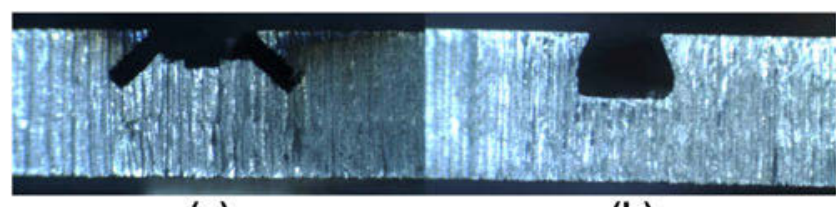

(a)

(b)

FIG. 11. Friction stir extrusion edge preparation (a) slit saw grove and (b) o ring dovetail grove, with permission from Ref. 150.

through intense deformation of thermomechanical processing imposed by friction as well as mechanical stirring action. The change in transverse speed affects heat input and subsequently influences the formation of IMCs. It is observed by Haghshenas et al. ${ }^{149}$ that IMC transformation from $\mathrm{Al}_{5} \mathrm{Fe}_{2}$ to $\mathrm{AlFe}$ is reported with the change in transverse speed from higher to lower.

\section{FRICTION STIR EXTRUSION}

FSE is another friction-based joining technique applied to lap joint configuration of dissimilar Al-steel joints. The steel base material is kept below to the Al base material with special preparation such as slit saw grove and $\mathrm{o}$ ring dovetail grove ${ }^{150}$ as shown in Fig. 11. The FSE tool is similar to FSW tool, inserted into $\mathrm{Al}$ base material up to the prepared grove area at the side of steel material, and hence the penetration length of tool is certainly higher than the thickness of Al base material. However, the contact of tool pin with steel is totally avoided with minor insertion in grove design on the steel material. ${ }^{150}$ The tool wear is drastically reduced as the pin is only stirring into the Al base material, which is easy to deform $\mathrm{Al}$ relative to the steel base material. Besides, the mixing of both the materials is not like mentioned in FSW. In the case of FSE, the Al base material is plastically deformed due to frictional heat produced. This solid state plastically deformed material is extruded to the steel grove that creates mechanical fixing of $\mathrm{Al}$ with steel along with diffusion bonding. However, the formation of IMCs is not reported with this type of manufacturing process that shows strong mechanical interlock between $\mathrm{Al}$ and steel with prepared grove. Out of two mentioned groves, slit saw grove has given better shear tensile strength relative to o ring dovetail grove. ${ }^{150}$

Same concept of FSE is utilized to obtain double sided bonding for Al-steel-Al base materials, which is named as two-sided friction stir riveting by extrusion. ${ }^{151}$ This technique is performed with the pin less tool with considered grove as the distance between two different steel plates in a sandwich structure of the Al-steel-Al base material. Two same tools are applied to the aforementioned base material from both the sides that in turn forms joint as mentioned above in FSE. ${ }^{150}$ Plastically deformed Al fills the cavity mentioned 


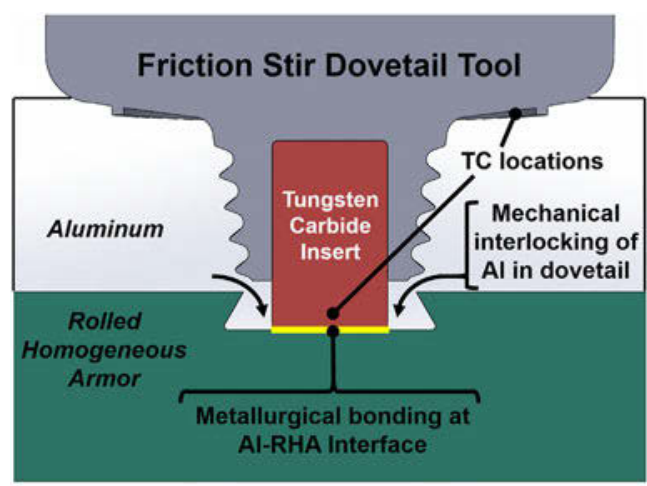

(a)

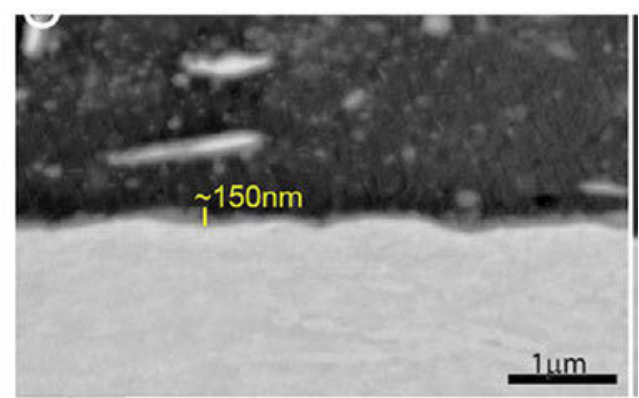

(b)

FIG. 12. Friction stir dovetailing (a) process description and (b) SEM image of joint interface, with permission from Ref. 152.

between two different steel plates, which subsequently joined with mechanical fixation. ${ }^{151}$ Therefore, authors of Ref. 151 have given name as friction stir riveting by extrusion.

\section{FRICTION STIR DOVETAILING}

FSD is a technique to join dissimilar Al-steel joints in a lap joint configuration for thick sections. Figure 12(a) shows the process description of FSD wherein $12.7 \mathrm{~mm}$ sectional thick workpieces of $\mathrm{Al}-$ steel are joined. ${ }^{152} \mathrm{~A}$ dovetail edge preparation is carried out before welding. The specially designed tool as shown in Fig. 12(a) is inserted into this dovetail groves up to the steel surface where tungsten carbide insert makes contact. This special edge preparation and tool design is able to obtain sound weld having mechanical interlocking along with strong metallurgical bonding. ${ }^{152}$ The formation of the IMC layer is suppressed with the help of FSD technique based on localized solid state deformational bonding. The submicrolevel IMC layer can be observed in Fig. 12(b) which is formed after excellent metallurgical bonding obtained by the FSD process. The thickness of the IMC interlayer is identified through high magnification microscopy as low as in the range of $40-150 \mathrm{~nm}$ in the case of FSD. ${ }^{152}$ The presence of $\mathrm{FeAl}_{3} \mathrm{IMCs}$ is observed during FSD while other phases of the Al-Fe binary diagram are not reported. ${ }^{152}$ It is suggested that FSD can help to obtain dissimilar Al-steel joint with superior lap shear strength relative to other friction stirred based processes. ${ }^{152}$ Major microstructural differences can be expected in the Al base material relative to the steel material as full pin is inside Al while not making significant contact to the steel base material.

\section{FRICTION BIT JOINING}

FBJ is a technique of making joints with the help of inserting bit of tool material into the joint surfaces.
Dissimilar materials can be joined with the help of the FBJ process. Lap joint configuration of Al-steel dissimilar combination can be joined with the help of specially designed bit made up of hardened steel. ${ }^{153} \mathrm{Al}$ is kept on top of the steel base material which makes deformation easy initially during plunging. Mechanical fixation and interlocking improve joining strength in the case of the FBJ process. The FBJ process can be the replacement of conventional mechanical fastening. The major problem associated in the case of Al-steel welding is formation of IMCs. This problem can be avoided up to the great extent as no metallurgical bonding is reported. ${ }^{153}$ The bit material and its design and plunging force are two most important considerations as far as the FBJ process is concerned.

\section{SUMMARY AND OUTLOOK}

Dissimilar Al-steel joints lead to the sustainable advantages such as overall cost reduction, weight minimization, and special properties. Due to this, different sectors of industries such as automotive, aerospace, and marine have rejuvenated the applications of Al-steel dissimilar joints. Development of this combination of dissimilar Al-steel system is very challenging considering complexity in metallurgy of dissimilar joints. A review on process description, influence of parameters, microstructural variations, formation of IMCs, and variations in mechanical properties is presented for various friction-based welding processes. Friction-based welding processes have proved their ability to prevail over the challenges observed in the case of dissimilar Al-steel joints. Developments in friction-based welding processes are increasing day by day with novel concepts to improve joint quality and hybrid properties taking into account its solid state advantages. Friction welding and FSW are considered as origin techniques from which further developments in welding processes are evolved. 
In the case of obtaining Al-steel friction-based welds, the interfacial reaction layers are formed of various IMC phases, which is advised to be as low as possible. Different approaches such as hybrid welding, process modification, use of interlayer material, heat input control, and post weld heat treatment processes can be implemented to suppress the formation of IMCs in terms of types and volume fraction. As frictional heat is involved in friction-based welding of Al-steel joints, solid state interdiffusion is reported as driving mechanism to form different phases of IMCs. Mechanical properties of these dissimilar joints are governed by the formation of IMCs. The increase in formation of IMCs increases hardness and brittleness while reduces tensile strength. Microstructural variations can be summarized as different based on applied processes. Large deformation in $\mathrm{Al}$ causes more grain size variations at $\mathrm{Al}$ side in most of the friction-based welding processes relative to the steel base material.

To the best of author's opinion, despite available articles related to $\mathrm{Al}$-steel joints, there is a large scope for research in the development of dissimilar Al-steel joints. The complexity involved in joining of this combination is observed interesting and needs to be fully understood with detailed studies for each and every friction-based welding processes. Limited joint configurations are reported that need to be resolved. There is a scarcity in data for each friction-based welding processes in terms of tool design, process parameters, and applicability for various base materials and different thicknesses.

\section{ABBREVIATIONS}

\begin{tabular}{ll}
\hline \hline Aluminum & Al \\
Intermetallic compounds & IMCs \\
Heat affected zone & HAZ \\
Thermo-mechanically affected zone & TMAZ \\
Friction stir welding & FSW \\
Hybrid friction stir welding & HFSW \\
Gas tungsten arc welding & GTAW \\
Friction stir spot welding & FSSW \\
Friction stir brazing & FSB \\
Friction melt bonding & FMB \\
Friction stir spot fusion welding & FSSFW \\
Friction stir extrusion & FSE \\
Friction stir assisted diffusion welding & FSADW \\
Friction stir dovetailing & FSD \\
Friction bit joining & FBJ \\
\hline \hline
\end{tabular}

\section{ACKNOWLEDGMENTS}

The work presented in this article is carried out as a part of the literature survey of sponsored project 39/14/ 02/2018-BRNS, funded by Board of research in nuclear sciences with Plasma and fusion research committee Institute for Plasma research, for which author is grateful.

\section{REFERENCES}

1. M.M. Atabaki, M. Nikodinovski, P. Chenier, J. Ma, M. Harooni, and R. Kovacevic: Welding of aluminum alloys to steels: An overview. J. Manuf. Sci. Prod. 14, 59 (2014).

2. R. Roth, J. Clark, and A. Kelkar: Automobile bodies: Can aluminum be an economical alternative to steel? JOM 53, 28 (2001).

3. S.A. Hussein, A.S.M. Tahir, and A.B. Hadzley: Characteristics of aluminum-to-steel joint made by friction stir welding: A review. Mater. Today Commun. 5, 32 (2015).

4. Y. Kusuda: Honda develops robotized FSW technology to weld steel and aluminum and applied it to a mass-production vehicle. Ind. Rob. 40, 208 (2013).

5. J.P. Clark: Future of Automotive Body Materials: Steel, Aluminum \& Polymer Composites. Presented at Hoogovens Technology Day, October 1998.

6. L.H. Shah and M. Ishak: Review of research progress on aluminum-steel dissimilar welding. Mater. Manuf. Process. 29. 928 (2014).

7. C.Y. Choi, D.C. Kim, D.G. Nam, Y.D. Kim, and Y.D. Park: A hybrid joining technology for aluminum/zinc coated steels in vehicles. J. Mater. Sci. Technol. 26, 858 (2010).

8. L. Agudo, D. Eyidi, C.H. Schmaranzer, E. Arenholz, N. Jank, J. Bruckner, and A.R. Pyzalla: Intermetallic $\mathrm{Fe}_{x} \mathrm{Al}_{y}$-phases in a steel/Al-alloy fusion weld. J. Mater. Sci. 42, 4205 (2007).

9. W. Liu, J. Ma, M. Mazar Atabaki, and R. Kovacevic: Joining of advanced high-strength steel to AA 6061 alloy by using Fe/Al structural transition joint. Mater. Des. 68, 146 (2015).

10. J. Ma, M. Harooni, B. Carlson, and R. Kovacevic: Dissimilar joining of galvanized high-strength steel to aluminum alloy in a zero-gap lap joint configuration by two-pass laser welding. Mater. Des. 58, 390 (2014).

11. G. Sierra, P. Peyre, F.D. Beaume, D. Stuart, and G. Fras: Steel to aluminium braze welding by laser process with $\mathrm{Al}-12 \mathrm{Si}$ filler wire. Sci. Technol. Weld. Joining 13, 430 (2008).

12. J. Sun, Q. Yan, Z. Li, and J. Huang: Effect of bevel angle on microstructure and mechanical property of $\mathrm{Al} /$ steel butt join using laser welding-brazing method. Mater. Des. 90, 468 (2016).

13. B.Y.M. Roulin, J.W. Luster, G. Karadeniz, and A. Mortensen: Strength and structure of furnace-brazed joints between aluminum and stainless steel. Weld. Res. 78, 151 (1999).

14. G. Sierra, P. Peyre, F. Deschaux Beaume, D. Stuart, and G. Fras: Galvanised steel to aluminium joining by laser and GTAW processes. Mater. Charact. 59, 1705 (2008).

15. R. Borrisutthekul, A. Seangsai, and W. Paonil: GTAW of zinccoated steel and aluminum alloy. Eng. J. 22, 39 (2018).

16. Y. Su, X. Hua, and Y. Wu: Quantitative characterization of porosity in $\mathrm{Fe}-\mathrm{Al}$ dissimilar materials lap joint made by gas metal arc welding with different current modes. J. Mater. Process. Technol. 214, 81 (2014).

17. Y. Su, X. Hua, and Y. Wu: Effect of input current modes on intermetallic layer and mechanical property of aluminum-steel lap joint obtained by gas metal arc welding. Mater. Sci. Eng. A 578, 340 (2013).

18. Q.M. Nguyen and S.C. Huang: An investigation of the microstructure of an intermetallic layer in welding aluminum alloys to steel by MIG process. Materials 8, 8246 (2015).

19. J. Sun, Q. Yan, W. Gao, and J. Huang: Investigation of laser welding on butt joints of Al/steel dissimilar materials. Mater. Des. 83, 120 (2015). 
20. G. Sierra, P. Peyre, F. Deschaux-Beaume, D. Stuart, and G. Fras: Steel to aluminium key-hole laser welding. Mater. Sci. Eng. A 447, 197 (2007).

21. X. He, P.W. Fuerschbach, and T. DebRoy: Heat transfer and fluid flow during laser spot welding of 304 stainless steel. $J$. Phys. D: Appl. Phys. 36, 1388 (2003).

22. M.J. Rathod and M. Kutsuna: Joining of aluminum alloy 5052 and low-carbon steel by laser roll welding. Weld. J. 83, 16 (2004).

23. S.W. Mei, M. Gao, J. Yan, C. Zhang, G. Li, and X.Y. Zeng: Interface properties and thermodynamic analysis of laser-arc hybrid welded Al/steel joint. Sci. Technol. Weld. Joining 18, 293 (2013).

24. Z. Ye, J. Huang, W. Gao, Y. Zhang, Z. Cheng, S. Chen, and J. Yang: Microstructure and mechanical properties of 5052 aluminum alloy/mild steel butt joint achieved by MIG-TIG double-sided arc welding-brazing. Mater. Des. 123, 69 (2017).

25. H. Bang, H. Bang, G. Jeon, I. Oh, and C. Ro: Gas tungsten arc welding assisted hybrid friction stir welding of dissimilar materials A16061-T6 aluminum alloy and STS304 stainless steel. Mater. Des. 37, 48 (2012).

26. M. Gao, C. Chen, S. Mei, L. Wang, and X. Zeng: Parameter optimization and mechanism of laser-arc hybrid welding of dissimilar $\mathrm{Al}$ alloy and stainless steel. Int. J. Adv. Manuf. Technol. 74, 199 (2014).

27. J. Chen, X. Yuan, Z. Hu, C. Sun, Y. Zhang, and Y. Zhang: Microstructure and mechanical properties of resistance-spotwelded joints for A5052 aluminum alloy and DP 600 steel. Mater. Charact. 120, 45 (2016).

28. M. Pouranvari: Critical assessment: Dissimilar resistance spot welding of aluminium/steel: Challenges and opportunities. Mater. Sci. Technol. 33, 1705 (2017).

29. N. Chen, H.P. Wang, B.E. Carlson, D.R. Sigler, and M. Wang: Fracture mechanisms of $\mathrm{Al} /$ steel resistance spot welds in lap shear test. J. Mater. Process. Technol. 243, 347 (2017).

30. M. Acarer and B. Demir: An investigation of mechanical and metallurgical properties of explosive welded aluminum-dual phase steel. Mater. Lett. 62, 4158 (2008).

31. K.J. Lee, S. Kumai, T. Arai, and T. Aizawa: Interfacial microstructure and strength of steel/aluminum alloy lap joint fabricated by magnetic pressure seam welding. Mater. Sci. Eng. A 471, 95 (2007).

32. T. Aizawa, M. Kashani, and K. Okagawa: Application of magnetic pulse welding for aluminum alloys and SPCC steel sheet joints. Weld. J. 86, 119 (2007).

33. H.T. Zhang, J.C. Feng, P. He, B.B. Zhang, J.M. Chen, and L. Wang: The arc characteristics and metal transfer behaviour of cold metal transfer and its use in joining aluminium to zinccoated steel. Mater. Sci. Eng. A 499, 111 (2009).

34. H.T. Zhang, J.C. Feng, and P. He: Interfacial phenomena of cold metal transfer (CMT) welding of zinc coated steel and wrought aluminium. Mater. Sci. Technol. 24, 1346 (2008).

35. J. Tsujino, K. Hidai, A. Hasegawa, R. Kanai, H. Matsuura, K. Matsushima, and T. Ueoka: Ultrasonic butt welding of aluminum, aluminum alloy and stainless steel plate specimens. Ultrasonics 40, 371 (2002).

36. H. Springer, A. Kostka, E.J. Payton, D. Raabe, A. KaysserPyzalla, and G. Eggeler: On the formation and growth of intermetallic phases during interdiffusion between low-carbon steel and aluminum alloys. Acta Mater 59, 1586 (2011).

37. F. Haidara, M.C. Record, B. Duployer, and D. Mangelinck: Phase formation in Al-Fe thin film systems. Intermetallics 23, 143 (2012).

38. M. Potesser, T. Schoeberl, H. Antrekowitsch, and J. Bruckner: The characterization of the intermetallic $\mathrm{Fe}-\mathrm{Al}$ layer of steelaluminum weldings. EPD Congr. 1, 167 (2006).
39. S.D. Meshram, T. Mohandas, and G.M. Reddy: Friction welding of dissimilar pure metals. J. Mater. Process. Technol. 184, 330 (2007).

40. W. Li, A. Vairis, M. Preuss, and T. Ma: Linear and rotary friction welding review. Int. Mater. Rev. 61, 71 (2016).

41. E. Taban, J.E. Gould, and J.C. Lippold: Dissimilar friction welding of 6061-T6 aluminum and AISI 1018 steel: Properties and microstructural characterization. Mater. Des. 31, 2305 (2010).

42. S. Fukumoto, H. Tsubakino, K. Okita, M. Aritoshi, and T. Tomita: Friction welding process of 5052 aluminium alloy to 304 stainless steel. Mater. Sci. Technol. 15, 1080 (1999).

43. S. Fukumoto, H. Tsubakino, T. Ono, M. Aritoshi, T. Tomita, and K. Okita: Formation process of reaction layer between aluminium alloys and stainless steel by friction welding. Weld. Int. 16, 941 (2002).

44. W.M. Gan, M. Hofmann, V. Ventzke, C. Randau, Y.D. Huang, A. Kriele, H.G. Brokmeier, and M. Mueller: Microstructure and residual stress in rotary friction welded dissimilar metals of AA7020 aluminium alloy with $316 \mathrm{~L}$ steel. Mater. Sci. Forum 879, 572 (2016).

45. S. Herbst, H. Aengeneyndt, H.J. Maier, and F. Nürnberger: Microstructure and mechanical properties of friction welded steel-aluminum hybrid components after T6 heat treatment. Mater. Sci. Eng. A 696, 33 (2017).

46. K. Ikeuchi, M. Takahashi, H. Watanabe, and M. Aritoshi: Effects of carbon content on intermetallic compound layer and joint strength in friction welding of $\mathrm{Al}$ alloy to steel. Weld. World $\mathbf{5 3}$, R135 (2009).

47. M. Ashfaq, N. Sajja, H. Khalid Rafi, and K. Prasad Rao: Improving strength of stainless steel/aluminum alloy friction welds by modifying faying surface design. J. Mater. Eng. Perform. 22, 376 (2013).

48. M. Yilmaz, M. Çöl, and M. Acet: Interface properties of aluminum/steel friction-welded components. Mater. Charact. 49, 421 (2002).

49. M. Kimura, M. Kusaka, K. Kaizu, K. Nakata, and K. Nagatsuka: Friction welding technique and joint properties of thin-walled pipe friction-welded joint between type 6063 aluminum alloy and AISI 304 austenitic stainless steel. Int. J. Adv. Manuf. Technol. 82, 489 (2016).

50. M. Kimura, K. Suzuki, M. Kusaka, and K. Kaizu: Effect of friction welding condition on joining phenomena and mechanical properties of friction welded joint between 6063 aluminium alloy and AISI 304 stainless steel. J. Manuf. Process. 26, 178 (2017)

51. M.G. Reddy, S.A. Rao, and T. Mohandas: Role of electroplated interlayer in continuous drive friction welding of AA6061 to AISI 304 dissimilar metals. Sci. Technol. Weld. Joining 13, 619 (2008).

52. A.Z. Sahin and B.S. Yilbas: Friction welding of Al-Al, Al-steel, and steel-steel samples. J. Mater. Eng. Perform. 5, 89 (1996).

53. T. Shinoda, K. Miyahara, M. Ogawa, and S. Endo: Friction welding of aluminium and plain low carbon steel. Weld. Int. 15, 438 (2001).

54. L. Wan and Y. Huang: Friction welding of AA6061 to AISI 316L steel: Characteristic analysis and novel design equipment. Int. J. Adv. Manuf. Technol. 95, 4117 (2018).

55. R. Mishra, P. Sarathi De, and N. Kumar: Friction Stir Welding and Processing (Springer International Publishing, Basel, Switzerland, 2014).

56. K. Mehta: Advanced joining and welding techniques: An overview. In Advanced Manufacturing Technologies. Materials Forming, Machining and Tribology, K. Gupta, ed. (Springer, Cham, 2017); pp. 101-136.

57. K.P. Mehta and V.J. Badheka: Influence of tool design and process parameters on dissimilar friction stir welding of copper 
to AA6061-T651 joints. Int. J. Adv. Manuf. Technol. 80, 20732082 (2015).

58. T. Zappia, M.T.S.S. Corporation, C. Smith, F.S. Link, and K. Colligan: Friction stir welding equipment. In Friction Stir Welding from Basics to Applications, D. Lohwasser and Z. Chen, eds. (Woodhead Publishing Limited, 2010).

59. R.S. Mishra and M.W. Mahoney, eds.: Friction Stir Welding and Processing. (ASTM International, Materials Park, Ohio, 2007).

60. K.P. Mehta and V.J. Badheka: Effects of tilt angle on the properties of dissimilar friction stir welding copper to aluminum. Mater. Manuf. Process. 31, 255 (2016).

61. K.P. Mehta and V.J. Badheka: Hybrid approaches of assisted heating and cooling for friction stir welding of copper to aluminum joints. J. Mater. Process. Technol. 239, 336 (2017).

62. K.P. Mehta and V.J. Badheka: Effects of tool pin design on formation of defects in dissimilar friction stir welding. Procedia Technol 23, 513 (2016).

63. K.P. Mehta and V.J. Badheka: A review on dissimilar friction stir welding of copper to aluminum: Process, properties, and variants. Mater. Manuf. Process. 31, 233 (2016).

64. Y.C. Chen and K. Nakata: Microstructural characterization and mechanical properties in friction stir welding of aluminum and titanium dissimilar alloys. Mater. Des. 30, 469 (2009).

65. L.H. Shah, N.H. Othman, and A. Gerlich: Review of research progress on aluminium-magnesium dissimilar friction stir welding. Sci. Technol. Weld. Joining 1718, 1 (2017).

66. Y.C. Chen and K. Nakata: Effect of tool geometry on microstructure and mechanical properties of friction stir lap welded magnesium alloy and steel. Mater. Des. 30, 3913 (2009).

67. M. Fazel-Najafabadi, S.F. Kashani-Bozorg, and A. Zarei-Hanzaki: Joining of CP-Ti to 304 stainless steel using friction stir welding technique. Mater. Des. 31, 4800 (2010).

68. R. Sengupta, S. Chakraborty, S. Bandyopadhyay, S. Dasgupta, R. Mukhopadhyay, K. Auddy, and A.S. Deuri: A short review on rubber/clay nanocomposites with emphasis on mechanical properties. Engineering 47, 21 (2007).

69. T. Watanabe, H. Takayama, and A. Yanagisawa: Joining of aluminum alloy to steel by friction stir welding. J. Mater. Process. Technol. 178, 342 (2006).

70. R.P. Mahto, R. Bhoje, S.K. Pal, H.S. Joshi, and S. Das: A study on mechanical properties in friction stir lap welding of AA 6061T6 and AISI 304. Mater. Sci. Eng. A 652, 136 (2016).

71. Q. Zheng, X. Feng, Y. Shen, G. Huang, and P. Zhao: Dissimilar friction stir welding of $6061 \mathrm{Al}$ to 316 stainless steel using $\mathrm{Zn}$ as a filler metal. J. Alloys Compd. 686, 693 (2016).

72. B. Sadeghian, A. Taherizadeh, and M. Atapour: Simulation of weld morphology during friction stir welding of aluminum-stainless steel joint. J. Mater. Process. Technol. 259, 96-108 (2018).

73. A. Yazdipour and A. Heidarzadeh: Dissimilar butt friction stir welding of Al 5083-H321 and 316L stainless steel alloys. Int. J. Adv. Manuf. Technol. 87, 3105 (2016).

74. K.K. Ramachandran, N. Murugan, and S. Shashi Kumar: Influence of tool traverse speed on the characteristics of dissimilar friction stir welded aluminium alloy, AA5052 and HSLA steel joints. Arch. Civ. Mech. Eng. 15, 822 (2015).

75. M. Elyasi, H.A. Derazkola, and M. Hosseinzadeh: Investigations of tool tilt angle on properties friction stir welding of A441 AISI to AA1100 aluminium. Proc. Inst. Mech. Eng., Part B 230, 1234 (2016).

76. X. Fei, X. Jin, Y. Ye, T. Xiu, and H. Yang: Effect of pre-hole offset on the property of the joint during laser-assisted friction stir welding of dissimilar metals steel and aluminum alloys. Mater. Sci. Eng., A 653, 43 (2016).

77. M. Abbasi, M. Dehghani, H.U. Guim, and D.I. Kim: Investigation of Fe-rich fragments in aluminum-steel friction stir welds via simultaneous Transmission Kikuchi Diffraction and EDS Acta Mater. 117, 262 (2016)

78. X. Liu, S. Lan, and J. Ni: Analysis of process parameters effects on friction stir welding of dissimilar aluminum alloy to advanced high strength steel. Mater. Des. 59, 50 (2014).

79. R.S. Coelho, A. Kostka, J.F. dos Santos, and A. Kaysser-Pyzalla: Friction-stir dissimilar welding of aluminium alloy to high strength steels: Mechanical properties and their relation to microstructure. Mater. Sci. Eng., A 556, 175 (2012).

80. J.T. Xiong, J.L. Li, J.W. Qian, F.S. Zhang, and W.D. Huang: High strength lap joint of aluminium and stainless steels fabricated by friction stir welding with cutting pin. Sci. Technol. Weld. Joining 17, 196 (2012).

81. M. Dehghani, A. Amadeh, and S.A.A. Akbari Mousavi: Investigations on the effects of friction stir welding parameters on intermetallic and defect formation in joining aluminum alloy to mild steel. Mater. Des. 43, 433-441 (2013).

82. K. Chen, X. Liu, and J. Ni: Keyhole refilled friction stir spot welding of aluminum alloy to advanced high strength steel. $J$. Mater. Process. Technol. 249, 452 (2017).

83. J. Tang and Y. Shen: Effects of preheating treatment on temperature distribution and material flow of aluminum alloy and steel friction stir welds. J. Manuf. Process. 29, 29 (2017).

84. T. Wang, H. Sidhar, R.S. Mishra, Y. Hovanski, P. Upadhyay, and B. Carlson: Friction stir scribe welding technique for dissimilar joining of aluminium and galvanised steel. Sci. Technol. Weld. Joining 23, 249 (2018).

85. K. Kimapong and T. Watanabe: Friction stir welding of aluminum alloy to steel. Weld. J. 83, 277 (2004).

86. X. Liu, S. Lan, and J. Ni: Electrically assisted friction stir welding for joining Al 6061 to TRIP 780 steel. J. Mater Process. Technol. 219, 112 (2015).

87. M. Dehghani, S.A.A.A. Mousavi, and A. Amadeh: Effects of welding parameters and tool geometry on properties of 3003 H18 aluminum alloy to mild steel friction stir weld. Trans. Nonferrous Met. Soc. China 23, 1957 (2013).

88. A. Yazdipour and A. Heidarzadeh: Effect of friction stir welding on microstructure and mechanical properties of dissimilar $\mathrm{Al}$ 5083-H321 and 316L stainless steel alloy joints. J. Alloys Compd. 680, 595 (2016).

89. H.A. Derazkola, M. Elyasi, and M. Hossienzadeh: Feasibility study on aluminum alloys and A441 steel joints by friction stir welding. Int. J. Adv. Des. Manuf. Technol. 7, 99 (2014).

90. C.M. Chen and R. Kovacevic: Joining of Al 6061 alloy to AISI 1018 steel by combined effects of fusion and solid state welding. Int. J. Mach. Tool Manufact. 44, 1205 (2004).

91. I. Ibrahim, Y. Uematsu, T. Kakiuchi, Y. Tozaki, and Y. Mizutani: Fatigue behaviour of dissimilar Al alloy/galvanised steel friction stir spot welds fabricated by scroll grooved tool without probe. Sci. Technol. Weld. Joining 20, 670 (2015).

92. Z. Shen, Y. Chen, M. Haghshenas, and A.P. Gerlich: Role of welding parameters on interfacial bonding in dissimilar steel/aluminum friction stir welds. Eng. Sci. Technol. Int. J. 18, 270 (2015).

93. B. Murugan, G. Thirunavukarasu, S. Kundu, S.V. Kailas, and S. Chatterjee: Interfacial microstructure and mechanical properties of friction stir welded joints of commercially pure aluminum and 304 stainless steel. J. Mater. Eng. Perform. 27, 2921 (2018).

94. H. Das, S.S. Jana, T.K. Pal, and A. De: Numerical and experimental investigation on friction stir lap welding of aluminium to steel. Sci. Technol. Weld. Joining 19, 69 (2014).

95. E.E. Patterson, Y. Hovanski, and D.P. Field: Microstructural characterization of friction stir welded aluminum-steel joints. Metall. Mater. Trans. A 47, 2815-2829 (2016).

96. Y.C. Chen and K. Nakata: Effect of the surface state of steel on the microstructure and mechanical properties of dissimilar metal 
lap joints of aluminum and steel by friction stir welding. Metall. Mater. Trans. A 39, 1985 (2008).

97. Z.W. Chen, S. Yazdanian, and G. Littlefair: Effects of tool positioning on joint interface microstructure and fracture strength of friction stir lap Al-to-steel welds. J. Mater. Sci. 48, 2624 (2013).

98. H. Das, R.N. Ghosh, and T.K. Pal: Study on the formation and characterization of the intermetallics in friction stir welding of aluminum alloy to coated steel sheet lap joint. Metall. Mater. Trans. A 45, 5098 (2014).

99. H. Das, A. Kumar, K.V. Rajkumar, T. Saravanan, T. Jayakumar, and T.K. Pal: Nondestructive evaluation of friction stir-welded aluminum alloy to coated steel sheet lap joint. J. Mater. Eng. Perform. 24, 4192 (2015).

100. A. Elrefaey, M. Gouda, M. Takahashi, and K. Ikeuchi: Characterization of aluminum/steel lap joint by friction stir welding. $J$. Mater. Eng. Perform. 14, 10 (2005).

101. R.N. Shubhavardhan and S. Surendran: Microstructure and fracture behavior of friction stir lap welding of dissimilar metals. Eng. Solid Mech. 6, 1-10 (2018).

102. W.H. Jiang and R. Kovacevic: Feasibility study of friction stir welding of 6061-T6 aluminium alloy with AISI 1018 steel. Proc. Inst. Mech. Eng., Part B 218, 1323 (2004).

103. H. Uzun, C. Dalle Donne, A. Argagnotto, T. Ghidini, and C. Gambaro: Friction stir welding of dissimilar Al 6013-T4 to X5CrNi18-10 stainless steel. Mater. Des. 26, 41 (2005).

104. Z.W. Chen and S. Yazdanian: Microstructures in interface region and strengths of friction stir lap Al-to-steel and Al-to-Ti welds. In Proceedings of 1st International Joint Symposium on Joining and Welding, H. Fuji, ed. (Woodhead Publishing, Cambridge, United Kingdom, 2013); pp. 231-235.

105. M. Ghosh, A. Kar, K. Kumar, and S.V. Kailas: Structural characterisation of reaction zone for friction stir welded aluminium-stainless steel joint. Mater. Technol. 27, 169 (2012).

106. M. Ghosh, R.K. Gupta, and M.M. Husain: Friction stir welding of stainless steel to al alloy: Effect of thermal condition on weld nugget microstructure. Metall. Mater. Trans. A 45, 854 (2014).

107. H. Das, S. Basak, G. Das, and T.K. Pal: Influence of energy induced from processing parameters on the mechanical properties of friction stir welded lap joint of aluminum to coated steel sheet. Int. J. Adv. Manuf. Technol. 64, 1653 (2013).

108. W.B. Lee, M. Schmuecker, U.A. Mercardo, G. Biallas, and S.B. Jung: Interfacial reaction in steel-aluminum joints made by friction stir welding. Scr. Mater. 55, 355 (2006).

109. C. Leitao, E. Arruti, E. Aldanondo, and D.M. Rodrigues: Aluminium-steel lap joining by multipass friction stir welding. Mater. Des. 106, 153 (2016).

110. E.A.T. López and A.J. Ramirez: Effect of process parameters in obtaining aluminium-steel joints and their microstructure by friction stir welding (FSW). Weld. Int. 29, 689 (2015).

111. M. Movahedi, A.H. Kokabi, S.M.S. Reihani, and H. Najafi: Effect of tool travel and rotation speeds on weld zone defects and joint strength of aluminium steel lap joints made by friction stir welding. Sci. Technol. Weld. Joining 17, 162 (2012).

112. M. Movahedi, A.H. Kokabi, S.M. Seyed Reihani, W.J. Cheng, and C.J. Wang: Effect of annealing treatment on joint strength of aluminum/steel friction stir lap weld. Mater. Des. 44, 487 (2013).

113. M. Pourali, A. Abdollah-zadeh, T. Saeid, and F. Kargar: Influence of welding parameters on intermetallic compounds formation in dissimilar steel/aluminum friction stir welds. $J$. Alloys Compd. 715, 1 (2017).

114. W. Ratanathavorn, A. Melander, and H. Magnusson: Intermetallic compounds in friction stirred lap joints between AA5754/ galvanised ultra-high strength steel. Sci. Technol. Weld. Joining 21, 653 (2016)

115. W. Ratanathavorn and A. Melander: Influence of zinc on intermetallic compounds formed in friction stir welding of AA5754 aluminium alloy to galvanised ultra-high strength steel. Sci. Technol. Weld. Joining 22, 673 (2017).

116. M. Shamsujjoha, B.K. Jasthi, M. West, and C. Widener: Friction stir lap welding of aluminum to steel using refractory metal pin tools. J. Eng. Mater. Technol. 137, 21009 (2015).

117. G. Sorger, H. Wang, P. Vilaça, and T.G. Santos: FSW of aluminum AA5754 to steel DX54 with innovative overlap joint. Weld. World 61, 257 (2017).

118. H. Springer, A. Kostka, J.F. dos Santos, and D. Raabe: Influence of intermetallic phases and Kirkendall-porosity on the mechanical properties of joints between steel and aluminium alloys. Mater. Sci. Eng. A 528, 4630 (2011).

119. T. Tanaka, T. Morishige, and T. Hirata: Comprehensive analysis of joint strength for dissimilar friction stir welds of mild steel to aluminum alloys. Scr. Mater. 61, 756 (2009).

120. S. Yazdanian: Metallurgical studies of friction stir lap welding. Ph.D. thesis, Auckland University of Technology, Aukland, New Zealand, 2012.

121. K.P. Mehta and V.J. Badheka: Influence of tool pin design on properties of dissimilar copper to aluminum friction stir welding. Trans. Nonferrous Met. Soc. China 27, 36-54 (2017).

122. B. Seo, K.H. Song, and K. Park: Corrosion properties of dissimilar friction stir welded 6061 aluminum and HT590 steel. Met. Mater. Int. 1-9 (2018), doi.org/10.1007/s12540-018-0135-2.

123. S. Bozzi, A.L. Helbert-Etter, T. Baudin, B. Criqui, and J.G. Kerbiguet: Intermetallic compounds in Al 6016/IF-steel friction stir spot welds. Mater. Sci. Eng. A 527, 4505 (2010).

124. M. Geiger, F. Micari, M. Merklein, L. Fratini, D. Contorno, A. Giera, and D. Staud: Friction stir knead welding of steel aluminium butt joints. Int. J. Mach. Tool Manufact. 48, 515 (2008).

125. X. Fei, X. Jin, N. Peng, Y. Ye, S. Wu, and H. Dai: Effects of filling material and laser power on the formation of intermetallic compounds during laser-assisted friction stir butt welding of steel and aluminum alloys. Appl. Phys. A Mater. Sci. Process. 122, 1 (2016).

126. S.W. Kallee: Industrial applications of friction stir welding. In Friction Stir Welding: Basics to Applications, D. Lohwasser and Z. Chen, eds. (Woodhead Publishing Limited, Cambridge, United Kingdom, 2009); pp. 118-163.

127. H. Dong, S. Chen, Y. Song, X. Guo, X. Zhang, and Z. Sun: Refilled friction stir spot welding of aluminum alloy to galvanized steel sheets. Mater. Des. 94, 457 (2016).

128. K. Feng, M. Watanabe, and S. Kumai: Microstructure and joint strength of friction stir spot welded 6022 aluminum alloy sheets and plated steel sheets. J. Japan Inst. Light Met. 61, 463 (2011).

129. E. Fereiduni, M. Movahedi, and A.H. Kokabi: Aluminum/steel joints made by an alternative friction stir spot welding process. $J$. Mater. Process. Technol. 224, 1 (2015).

130. Y. Ding, Z. Shen, and A.P. Gerlich: Refill friction stir spot welding of dissimilar aluminum alloy and AlSi coated steel. $J$. Manuf. Process. 30, 353 (2017).

131. X. Lyu, M. Li, X. Li, and J. Chen: Double-sided friction stir spot welding of steel and aluminum alloy sheets. Int. J. Adv. Manuf. Technol. 96, 2875-2884 (2018).

132. K. Chen, X. Liu, and J. Ni: Effects of process parameters on friction stir spot welding of aluminum alloy to advanced highstrength steel. J. Manuf. Sci. Eng. 139, 81016 (2017). 
133. E. Fereiduni, M. Movahedi, and A.H. Kokabi: Dissimilar Al/steel friction stir spot welding: To penetrate into the lower steel sheet or not? Sci. Technol. Weld. Joining 21, 466 (2016).

134. K. Kurtenbach: Dissimilar Friction Stir Spot Welding of Aluminum to Steel for Use in the Automotive Industry. Report for South Dakota School of Mines and Technology, Rapid City, South Dakota (2013).

135. P. Jedrasiak, H.R. Shercliff, A. Reilly, G.J. McShane, Y.C. Chen, L. Wang, J. Robson, and P. Prangnell: Thermal modeling of $\mathrm{Al}-\mathrm{Al}$ and $\mathrm{Al}-$ steel friction stir spot welding. J. Mater. Eng. Perform. 25, 4089 (2016)

136. T. Liyanage, J. Kilbourne, A.P. Gerlich, and T.H. North: Joint formation in dissimilar $\mathrm{Al}$ alloy/steel and $\mathrm{Mg}$ alloy/steel friction stir spot welds. Sci. Technol. Weld. Joining 14, 500 (2009).

137. J.M. Piccini and H.G. Svoboda: Tool geometry optimization in friction stir spot welding of Al-steel joints. J. Manuf. Process. 26, 142 (2017).

138. J.M. Piccini and H.G. Svoboda: Effect of pin length on friction stir spot welding (FSSW) of dissimilar aluminum-steel joints. Procedia Mater. Sci. 9, 504 (2015).

139. Y.C. Chen, A. Gholinia, and P.B. Prangnell: Interface structure and bonding in abrasion circle friction stir spot welding: A novel approach for rapid welding aluminium alloy to steel automotive sheet. Mater. Chem. Phys. 134, 459 (2012).

140. Z. Shen, J. Chen, Y. Ding, J. Hou, B. Shalchi Amirkhiz, K. Chan, and A.P. Gerlich: Role of interfacial reaction on the mechanical performance of $\mathrm{Al} / \mathrm{steel}$ dissimilar refill friction stir spot welds. Sci. Technol. Weld. Joining 1718, 1 (2017).

141. Y.F. Sun, H. Fujii, N. Takaki, and Y. Okitsu: Microstructure and mechanical properties of dissimilar Al alloy/steel joints prepared by a flat spot friction stir welding technique. Mater. Des. 47, 350 (2013).

142. V.X. Tran, J. Pan, and T. Pan: Fatigue behavior of spot friction welds in lap-shear and cross-tension specimens of dissimilar aluminum sheets. Int. J. Fatigue 32, 1022 (2010)

143. Y. Uematsu, T. Kakiuchi, Y. Tozaki, and H. Kojin: Comparative study of fatigue behaviour in dissimilar $\mathrm{Al}$ alloy/steel and $\mathrm{Mg}$ alloy/steel friction stir spot welds fabricated by scroll grooved tool without probe. Sci. Technol. Weld. Joining 17, 348 (2012).

144. V. Gupta, P. Upadhyay, L.S. Fifield, T. Roosendaal, X. Sun, P. Nelaturu, and B. Carlson: Linking process and structure in the friction stir scribe joining of dissimilar materials: A computational approach with experimental support. J. Manuf. Process. 32, 615 (2018).

145. G.F. Zhang, K. Zhang, Y. Guo, and J.X. Zhang: A comparative study of friction stir brazing and furnace brazing of dissimilar metal $\mathrm{Al}$ and $\mathrm{Cu}$ plates. Metallogr. Microstruct. Anal. 3, 272 (2014).

146. G. Zhang, W. Su, J. Zhang, and Z. Wei: Friction stir brazing: A novel process for fabricating $\mathrm{Al} /$ steel layered composite and for dissimilar joining of $\mathrm{Al}$ to steel. Metall. Mater. Trans. A 42, 2850 (2011)

147. C. Van Der Rest, P.J. Jacques, and A. Simar: On the joining of steel and aluminium by means of a new friction melt bonding process. Scr. Mater. 77, 25 (2014).

148. M.J. Hsieh, R.T. Lee, and Y.C. Chiou: Friction stir spot fusion welding of low-carbon steel to aluminum alloy. J. Mater Process. Technol. 240, 118 (2017).

149. M. Haghshenas, A. Abdel-Gwad, A.M. Omran, B. Gökçe, S. Sahraeinejad, and A.P. Gerlich: Friction stir weld assisted diffusion bonding of 5754 aluminum alloy to coated high strength steels. Mater. Des. 55, 442 (2014).

150. W.T. Evans, B.T. Gibson, J.T. Reynolds, A.M. Strauss, and G.E. Cook: Friction stir extrusion: A new process for joining dissimilar materials. Manuf. Lett. 5, 25 (2015).

151. W.T. Evans, C. Cox, B.T. Gibson, A.M. Strauss, and G.E. Cook: Two-sided friction stir riveting by extrusion: A process for joining dissimilar materials. J. Manuf. Process. 23, 115 (2016).

152. M. Reza-E-Rabby, K. Ross, N.R. Overman, M.J. Olszta, M. McDonnell, and S.A. Whalen: Joining thick section aluminum to steel with suppressed FeAl intermetallic formation via friction stir dovetailing. Scr. Mater. 148, 63 (2018).

153. M. Miles, S.T. Hong, and Y.H. Jeong: Spot welding of aluminum and cast iron by friction bit joining. Int. J. Precis. Eng. Manuf. 14, 1003 (2013). 